\title{
THE NOTCH MASTER CURVE: A PROPOSAL OF MASTER CURVE FOR FERRITIC-PEARLITIC STEELS IN NOTCHED CONDITIONS
}

\author{
S. Cicero, V. Madrazo, T. García \\ Dpto. Ciencia e Ingeniería del Terreno y de los Materiales, Universidad de Cantabria, Av/ Los \\ Castros s/n, 39005, Santander, Cantabria, Spain, ciceros@unican.es, Tel: 0034942200917
}

\begin{abstract}
This paper presents a model for the prediction of the apparent fracture toughness of ferriticpearlitic steels in notched conditions and operating at temperatures corresponding to their ductile-to-brittle transition zone. The model, here named the Notch-Master Curve, is based on the combination of the Master Curve of the material in cracked conditions and the notch corrections provided by the Theory of Critical Distances. In order to validate the model, the fracture resistance results obtained in 168 tests performed on CT specimens ( 84 for each material) are presented. These tests were carried out, for each material, in specimens with six different notch radii, from $0 \mathrm{~mm}$ up to $2.0 \mathrm{~mm}$, and at three different temperatures within their corresponding ductile-to-brittle transition zone. It has been observed that the model provides good predictions of the fracture resistance in notched conditions for the two materials analysed.
\end{abstract}

Keywords: Notch effect, Master Curve, Theory of Critical Distances, Reference temperature.

\section{INTRODUCTION}

In many situations, the load-bearing capacity of a structural component is conditioned by the existence of stress risers. These may have very different natures: cracks, notches, holes, welded joints, corners, etc, all of them having different approaches when the corresponding structural integrity is being analysed. This paper is focused on notch-type defects, which may appear in structural components due to design details (e.g., holes), mechanical damage (e.g., gouges), corrosion defects or fabrication defects. If such defects are blunt, it is overly conservative to proceed on the assumption that the defects behave like sharp cracks, coupled with the use of ordinary Fracture Mechanics. Such assumption may lead to unnecessary repairs or replacements, or to oversizing. Components with non-sharp defects or notches exhibit an apparent fracture toughness that is greater than that obtained in cracked components because of the lower stresses acting at the notch tip and the evolution of fracture micromechanisms, as shown in [1-5]. This generally has direct consequences on the load-bearing capacity of the component and also on the corresponding structural integrity assessments.

In this sense, recent years have seen a great deal of research aimed at providing a notch theory capable of predicting the fracture behavior of notched components, proposing two main failure criteria (e.g., [6,7]): the global fracture criteria and the local fracture criteria. Although both approaches are unquestionably significant from a scientific point of view, the local fracture criteria have more practical applications, especially those based on the Theory of Critical Distances (TCD) [8,9]. 
At the same time, it is known that the fracture resistance in cracked conditions of ferriticpearlitic steels presents a clear dependence on the working temperature, with brittle behaviour at low temperatures (generally referred to as the lower shelf, LS), ductile behaviour at high temperatures (upper shelf, US) and transition behaviour between the lower shelf and the upper shelf (ductile-to-brittle transition zone, DBTZ). Figure 1 represents a schematic of this type of behaviour. The DBTZ of ferritic-pearlitic steels in cracked conditions has been successfully modelled through de Master Curve (MC) [10-14], which is nowadays a fundamental tool in the design and in-service assessment of critical structural components (e.g., nuclear pressure vessels). However, to the knowledge of the authors the analysis of this temperature dependence has not been previously reported in the literature when dealing with ferritic-pearlitic materials in notched conditions.

With all this, this paper presents a model for the fracture behaviour of ferritic-pearlitic steels in notched conditions and operating within the material DBTZ. The model is based on the above mentioned MC and the notch corrections provided by the TCD. With this purpose, Section 2 gathers some theoretical background on both the TCD and the MC and presents the proposed model, here named the Notch-Master Curve (NMC), Section 3 describes the experimental programme that is used here to validate the model, and Section 4 presents the corresponding validation, which is performed by comparison between the experimental results and the NMC predictions. Finally, Section 5 gathers the conclusions.

\section{THEORETICAL BACKGROUND AND THE NOTCH-MASTER CURVE}

\subsection{The Theory of Critical Distances}

The Theory of Critical Distances (TCD) is in reality a group of methodologies with a common aspect: they all consider a characteristic material length parameter (the critical distance, L) when performing fracture assessments $[8,9]$. The critical distance is defined as follows:

$L=\frac{1}{\pi}\left(\frac{K_{c}}{\sigma_{0}}\right)^{2}$

where $\mathrm{K}_{\mathrm{c}}$ is the material fracture toughness and $\sigma_{0}$ is a strength parameter, named the inherent strength, which is usually larger than the ultimate tensile strength $\left(\sigma_{u}\right)$ and must be calibrated. The inherent strength and the ultimate tensile strength are equal only in those situations where the fracture is brittle at both the macro and the micro scales (e.g., fracture of ceramics).

The origins of the TCD date from the middle of the twentieth century, with the works of Neuber [15] and Peterson [16], but it has been in this century that this theory has been comprehensively analysed, establishing its applicability to different types of materials (i.e., metals, ceramics, polymers and composites), processes (fracture and fatigue) and conditions (e.g., linear-elastic vs. elastoplastic) (e.g., [1,2,17-23]). A complete review, description and analysis of the fundamentals, the applications and the limitations of the TCD may be found in [8].

Here, suffice it to say that among the different methodologies composing the TCD two of them are particularly simple and interesting from an engineering point of view, the Point Method (PM) and the Line Method (LM) [8]: 
- The PM establishes that fracture occurs when the stress reaches the inherent strength $\left(\sigma_{0}\right)$ at a distance from the defect tip equal to $L / 2$ :

$\sigma\left(\frac{L}{2}\right)=\sigma_{0}$

- The LM assumes that fracture occurs when the average stress along a distance equal to $2 \mathrm{~L}$ (starting from the defect tip), reaches the inherent strength, $\sigma_{0}$ :

$\frac{1}{2 L} \int_{0}^{2 L} \sigma(r) d r=\sigma_{0}$

The predictions provided by the LM are slightly different from those provided by the PM [8], but both methodologies provide results which are reasonably similar to the experimental ones (e.g., $[1,2,8])$

Furthermore, the PM and the LM provide expressions [8] for the apparent fracture toughness $\left(\mathrm{K}^{\mathrm{N}}\right.$ mat $)$ exhibited by notched components. Firstly, it is necessary to consider the stress distribution on the notch tip provided by Creager and Paris [24], which is equal to that ahead of the crack tip but displaced a distance equal to $\rho / 2$ along the $\mathrm{x}$-axis:

$\sigma(r)=\frac{K_{I}}{\sqrt{\pi}} \frac{2(r+\rho)}{(2 r+\rho)^{3 / 2}}$

Secondly, in case of using the PM, and considering both the definition of the critical distance L (equation (1)) and the corresponding fracture condition (equation (2)), and establishing that failure takes place when $\mathrm{K}_{\mathrm{I}}$ is equal to $\mathrm{K}^{\mathrm{N}}$ mat , equation (5) may be easily obtained:

$$
K_{m a t}^{N}=K_{m a t} \frac{\left(1+\frac{\rho}{L}\right)^{3 / 2}}{\left(1+\frac{2 \rho}{L}\right)}
$$

Analogously, the application of the LM provides equation (6), which provides a particularly simple estimation of the apparent fracture toughness:

$$
K_{\text {mat }}^{N}=K_{\text {mat }} \sqrt{1+\frac{\rho}{4 L}}
$$

These expressions, which provide similar results, may be used in the structural integrity assessment of notched components, as shown in [25]. 


\subsection{The Master Curve}

The Master Curve (MC) [10-14] constitutes a fracture characterisation tool for a wide variety of steels, mainly those of a ferritic nature, within their ductile-to-brittle transition zone (DBTZ). It is based on statistical considerations, related to the distribution of cleavage promoting particles around the crack tip. At the end, fracture is controlled by weakest link statistics and follows a three parameter Weibull distribution. Thus, within the scope of small-scale yielding conditions, the cumulative failure probability $\left(\mathrm{P}_{\mathrm{f}}\right)$ on which the $\mathrm{MC}$ is based follows equation (7):

$P_{f}=1-e^{-\frac{B}{B_{0}}\left(\frac{K_{J c}-K_{\min }}{K_{0}-K_{\min }}\right)^{b}}$

where $\mathrm{K}_{\mathrm{Jc}}$ is the fracture toughness for the selected failure probability $\left(\mathrm{P}_{\mathrm{f}}\right), \mathrm{K}_{0}$ is a scale parameter located at the $63.2 \%$ cumulative failure probability level, $\mathrm{B}$ is the specimen thickness and $\mathrm{B}_{0}$ is the reference specimen thickness assumed in this methodology $\left(\mathrm{B}_{0}=25 \mathrm{~mm}\right) . \mathrm{K}_{\text {min }}$ and $\mathrm{b}$ take the same values for all ferrritic steels and have been experimentally fitted, providing $20 \mathrm{MPam}^{1 / 2}$ and 4 respectively. In any case, it can be observed that the fracture characterization within the DBTZ is performed by using $\mathrm{K}_{\mathrm{Jc}}$, which is an elastic-plastic equivalent stress intensity factor derived from the $\mathrm{J}$-integral at the point of onset of cleavage fracture, $\mathrm{J}_{\mathrm{c}}$.

The dependence of $\mathrm{K}_{0}$ on temperature under cleavage fracture conditions follows equation (8) [10-12,26]:

$$
K_{0}=31+77 e^{0.019 \cdot\left[T-T_{0}\right]}
$$

where $\mathrm{T}_{0}$ is the reference temperature, which corresponds to the temperature where the median fracture toughness for a $25 \mathrm{~mm}$ thick specimen is $100 \mathrm{MPam}^{1 / 2}$. Therefore, the only parameter required to determine the temperature dependence of $\mathrm{K}_{\mathrm{Jc}}$ is the material reference temperature. Moreover, whichever the ferritic steel is, and once the corresponding $\mathrm{T}_{0}$ is known, it is possible to define the $\mathrm{MC}$ for any probability of failure $\left(\mathrm{P}_{\mathrm{f}}\right)$ :

$$
K_{J c, P_{f}}=20+\left(-\ln \left(1-P_{f}\right)\right)^{0.25}\left(11+77 e^{0.019\left(T-T_{0}\right)}\right)
$$

Thus, in $25 \mathrm{~mm}$ thick specimens, the curves associated to probabilities of failure of $95 \%, 50 \%$ and 5\% are, respectively, those gathered in equations (10), (11) and (12):

$$
\begin{aligned}
& K_{J c 0.95}=34.5+101.3 \cdot e^{0.019\left(T-T_{0}\right)} \\
& K_{J c 0.50}=30+70 \cdot e^{0.019\left(T-T_{0}\right)} \\
& K_{J c 0.05}=25.2+36.6 \cdot e^{0.019\left(T-T_{0}\right)}
\end{aligned}
$$

The experimental and analytical procedure that allows $\mathrm{T}_{0}$ to be determined is gathered in [14]. The transcendence of this engineering tool is enormous, given that it allows all kind of ferritic 
steels to be characterised within their corresponding DBTZ using a single parameter, $\mathrm{T}_{0}$, whose determination is completely standardised.

\subsection{The Notch-Master Curve}

Once both the TCD and the MC fundamentals have been outlined, this paper proposes to combine them in order to provide an apparent fracture toughness estimation of ferritic steels operating in the DBTZ. The assumptions are the following:

- The reference temperature, $\mathrm{T}_{0}$, on which the $\mathrm{MC}$ is based, is a material constant regardless of the type of defect being analysed. Therefore this parameter has full validity in notched conditions.

- The notch corrections provided by the TCD (e.g., PM and LM) generate similar estimations of the apparent fracture toughness. This has been widely reported in [1-3,8]. For the sake of simplicity, the notch correction provided by the LM will be used here (equation (6)), but the expressions shown below would be totally analogous in case of using any other methodology included within the TCD (e.g., equation (5), provided by the PM).

- Although the TCD has a linear-elastic nature, it generates good predictions of apparent fracture toughness and load bearing capacity under (limited) elastic-plastic conditions, such as those existing within the DBTZ, provided the calibration of the TCD parameters is conveniently performed. A comprehensive example of this circumstance may be found in [21].

With all this, the expressions of the Notch-Master Curve (NMC) proposed here are straightforward. These would be equations (13), (14) and (15) for probabilities of failure of $95 \%, 50 \%$ and $5 \%$, respectively:

$$
\begin{aligned}
& K_{J c 0.95}^{\mathrm{N}}=\left[34.5+101.3 \cdot e^{0.019\left(T-T_{0}\right)}\right] \sqrt{1+\frac{\rho}{4 L}} \\
& K_{J c 0.50}^{N}=\left[30+70 \cdot e^{0.019\left(T-T_{0}\right)}\right] \sqrt{1+\frac{\rho}{4 L}} \\
& K_{J c 0.05}^{N}=\left[25.2+36.6 \cdot e^{0.019\left(T-T_{0}\right)}\right] \sqrt{1+\frac{\rho}{4 L}}
\end{aligned}
$$

Analogous expressions could be easily derived for any other probability of failure $\left(\mathrm{P}_{\mathrm{f}}\right)$ by combining equation (9) with the LM notch correction.

Therefore, in order to define the NMC for a particular steel, it is necessary to determine $\mathrm{T}_{0}$, which is obtained by testing cracked specimens following [14], and the value of $L$ all along the DBTZ. This tool provides estimations of the apparent fracture toughness of ferritic steels containing notch-type defects and operating within the material DBTZ. 


\section{EXPERIMENTAL PROCEDURES}

The experimental program is composed of $168 \mathrm{CT}$ notched specimens, $25 \mathrm{~mm}$ thick, made of two different materials: steel S275JR and steel S355J2, both being ferritc-pearlitic steels. The specimens, LT oriented, were obtained from a $25 \mathrm{~mm}$ thick rolled plate. The notch radii being analysed are $0 \mathrm{~mm}$ (crack-type defect), $0.15 \mathrm{~mm}, 0.25 \mathrm{~mm}, 0.5 \mathrm{~mm}, 1.0 \mathrm{~mm}$ and $2.0 \mathrm{~mm}$. The specimens were tested at temperatures belonging the DBTZ. Steel S275JR, whose reference temperature is $-26^{\circ} \mathrm{C}$ [4], was tested at $-50^{\circ} \mathrm{C}$ ( 24 specimens, four per notch radius), $-30^{\circ} \mathrm{C}(24$ specimens) and $-10^{\circ} \mathrm{C}$ (36 specimens, six per notch radius), whereas steel $\mathrm{S} 355 \mathrm{~J} 2$, whose reference temperature is $-133^{\circ} \mathrm{C}$ [4], was tested at $-150^{\circ} \mathrm{C}$ (24 specimens), $-120^{\circ} \mathrm{C}(24$ specimens) and $-100^{\circ} \mathrm{C}(36$ specimens).

Table 1 gathers the tensile properties of the two materials at the different temperatures of interest. The tests were performed following [27].

Tables 2 and 3 gather the whole experimental program, and show the material, the geometry, the testing temperature and the apparent fracture toughness result of every single tested CT specimen. It can be seen that 8 of the tests do not have any result, given that the experimental procedure was not valid in those cases. The apparent fracture toughness $\left(\mathrm{K}^{\mathrm{N}}{ }_{\text {mat }}\right)$ obtained on each individual test has been determined following the procedure specified in [14] for the determination of $\mathrm{K}_{\mathrm{Jc}}$ in cracked specimens. Therefore:

$$
K_{m a t}^{N}=\sqrt{J_{m a t}^{N} \frac{E}{1-v^{2}}}
$$

where $\mathbf{J}^{\mathrm{N}}{ }_{\text {mat }}$ is the apparent $\mathrm{J}$-integral at onset of cleavage fracture, $\mathrm{E}$ is the Young's modulus and $v$ is the Poisson's ratio [14]:

$J_{\text {mat }}^{N}=J_{e}^{N}+J_{p}^{N}=\frac{\left(1-v^{2}\right)\left(K_{e}^{N}\right)^{2}}{E}+\frac{\eta A_{p}}{B b_{0}}$

where $\mathrm{J}^{\mathrm{N}}$ and $\mathrm{J}^{\mathrm{N}}$ p are, respectively, the elastic and plastic components of $\mathrm{J}^{\mathrm{N}}$ mat, $\eta$ is a dimensionless constant, $A_{p}$ is the plastic area under the load-displacement curve, $b_{0}$ is the initial remaining ligament, $\mathrm{B}$ the specimen thickness and $\mathrm{K}_{\mathrm{e}}^{\mathrm{N}}$ is the apparent elastic stress intensity factor at instability [14]:

$$
K_{e}^{N}=\left(\frac{P}{B \cdot W^{0.5}}\right) \frac{2+\frac{a}{W}}{\left(1-\frac{a}{W}\right)^{3 / 2}} \cdot\left(0.886+4.64\left(\frac{a}{W}\right)-13.32\left(\frac{a}{W}\right)^{2}+14.72\left(\frac{a}{W}\right)^{3}-5.60\left(\frac{a}{W}\right)^{4}\right)
$$

$\mathrm{P}$ is the applied load at onset of cleavage fracture, $\mathrm{W}$ the specimen width and a the defect length. Figures 2 and 3 show two examples of the types of curves obtained in the tests. 


\section{RESULTS AND DISCUSSION}

This section presents the validation of the NMC predictions (equations (13) to (15)), by their comparison to the experimental results gathered in Section 3 (equation (16)).

In order to apply equations (13) to (15), it is necessary to determine the critical distance. This may be performed by a combination of experimental work covering different notch radii (at least two different radii) and finite elements modelling, or by fitting experimental results also covering different notch radii (here, more than two radii are required) (e.g., [1-3,8]. This paper calibrates L using the second approach: Figures 4 and 5 show the L values, one per temperature, providing the best fit of the LM (equation (6)) to the experimental data. The values obtained are shown in Table 4.

Figure 6 shows the values of $\mathrm{L}$ for both steels, and the corresponding second order fitting equations. These are equations (19) and (20) for steels S275JR and S355J2, respectively:

$$
L=0.00000125 \cdot T^{2}+0.00016 \cdot T+0.009775
$$

$$
L=-0.0000084 \cdot T^{2}-0.001988 \cdot T-0.1008
$$

Equation (19) (in case of steel S275JR) and equation (20) (steel S355J2) may be introduced in equations (13) to (15) to provide apparent fracture toughness estimations. Moreover, although for each material there are differences between the three values of $\mathrm{L}$ obtained at the different temperatures, they all have the same order of magnitude and the effect of using one or another is mitigated by the fact that $\mathrm{L}$ is squared in the different expressions considering the notch effect. Thus, for the sake of simplicity, a constant value of $\mathrm{L}$ (the average value) is also considered (0.0064 $\mathrm{mm}$ for steel S275JR and $0.0136 \mathrm{~mm}$ for steel S355J2). With all this, figures 7 to 10 show the corresponding predictions of the NMC and their comparison with the experimental results.

Concerning steel S275JR (figures 7 and 8), these are the main observations:

- It can be observed that the MC (and the NMC) provides good predictions for cracked specimens.

- In case of specimens containing $0.15 \mathrm{~mm}$ notch radii, the predictions provided by the NMC are conservative, regardless of the L being used (equation (19) or average value). This is caused by the fitting process of the $\mathrm{K}^{\mathrm{N}}$ mat results provided by the TCD in Figure 4 , where the predictions for $0.15 \mathrm{~mm}$ notch radii are much lower than the experimental results. This has direct consequences on the NMC predictions.

- For notch radii from $0.25 \mathrm{~mm}$ up to $2.0 \mathrm{~mm}$, the predictions are reasonably good, again, regardless of the $L$ being used. In some cases (notch radii of $0.50 \mathrm{~mm}$ and $2.0 \mathrm{~mm}$ ) the predictions obtained when using equation (19) are slightly better than those obtained when using the average value of $\mathrm{L}$; in other cases (notch radii of $0.25 \mathrm{~mm}$ and $1.0 \mathrm{~mm}$ ), the average value provides better predictions.

- The predictions are good even in those cases with significant plasticity (e.g., $2.0 \mathrm{~mm}$ notch radius at higher temperatures), when the scope of both the TCD and the MC is theoretically exceeded. 
- The shape of the NMC obtained when using equation (19) is similar to that obtained when considering the average value of $\mathrm{L}$ (see Figure 11$)$. For low temperatures $\left(-50^{\circ} \mathrm{C}\right)$ within the temperature range considered, the average value provides more conservative predictions; for intermediate temperatures $\left(-30^{\circ} \mathrm{C}\right)$, both approaches provide basically identical results, and; for higher temperatures $\left(-10^{\circ} \mathrm{C}\right)$, the average value provides greater predictions of the apparent fracture toughness. Figure $6 a$ justifies this observation.

Thus, for steel S275JR, the NMC generally provides good predictions of the apparent fracture toughness within the material DBTZ. Such predictions are mostly located between the curves associated to probabilities of failure of 5\% and $95 \%$. Moreover, when the experimental results are not located between such lines, they are generally located above the curve associated to a $95 \%$ probability of failure, which means that the NMC predictions are conservative. Finally, there are very few experimental results below the 5\% curve ( 2 when using equation (19) and 1 when using the average value of $\mathrm{L}$ ), so non-conservative situations are very limited.

Concerning steel S355J2, some observations can also be highlighted:

- The MC provides good predictions in cracked specimens, although there is one experimental result located slightly below the $5 \%$ line (at $-150{ }^{\circ} \mathrm{C}$ ), and another experimental result located slightly above the $95 \%$ line (at $\left.-120^{\circ} \mathrm{C}\right)$.

- The results are reasonable for $0.15 \mathrm{~mm}$ notch radii, although there is one experimental result clearly located below the 5\% line (unsafe predictions of MC). This fact is justified by the fitting process of the $\mathrm{K}^{\mathrm{N}}$ mat results performed by using the TCD (Figure $5 \mathrm{c})$. Moreover, the average value of $\mathrm{L}$ provides better results than the value obtained by using equation (20).

- The predictions are also reasonable for notch radii from $0.25 \mathrm{~mm}$ up to $2.0 \mathrm{~mm}$, although there are several unsafe predictions at $-150{ }^{\circ} \mathrm{C}$. Again, the justification to this observation in in Figure $5 \mathrm{c}$ ): the high scatter obtained at this temperature means that the best fit curve provided by the TCD leaves some results well below. Finally, for these notch radii, the average value of $L$ provides better results than that obtained when using equation (20).

- As observed in steel S275JR, the predictions are also good in those cases with significant plasticity (e.g., $2.0 \mathrm{~mm}$ notch radius at higher temperatures).

- In this material, the shape of the NMC obtained when using equation (20) is rather different to that obtained when considering the average value of $\mathrm{L}$ (see Figure 12). For low temperatures $\left(-150^{\circ} \mathrm{C}\right)$ within the temperature range considered, the average value provides more conservative predictions; for intermediate and high temperatures (-120 ${ }^{\circ} \mathrm{C}$ and $-100^{\circ} \mathrm{C}$, respectively), the average value provides better predictions of the apparent fracture toughness.

Therefore, the predictions of the NMC in steel S355J2 have also been good, although less accurate than those obtained in steel S275JR. Steel 355J2 presents a higher number of experimental results located below the curve associated to a $5 \%$ probability of failure, all these results being located at $-150{ }^{\circ} \mathrm{C}$. The apparent fracture toughness results obtained at this temperature present a high scatter, and the MC itself also present a point below the $5 \%$ line. 


\section{CONCLUSIONS}

This paper presents the concept of Notch-Master Curve for the analysis of the apparent fracture toughness (that observed in notched conditions) within the ductile-to-brittle transition zone of ferritic-pearlitic steels, which may be applied to both the design and operation stages of structural components. With this aim, firstly, both the Theory of Critical Distances and the Master Curve are presented as scientific and engineering tools for the analysis of, respectively, the notch effect and the fracture toughness evolution within the ductile-to-brittle transition zone. Both methodologies are combined here to provide the Notch-Master Curve, which allows the evolution of the apparent fracture toughness within the ductile-to-brittle transition zone of ferritic-pearltic steels to be predicted.

In order to validate the Notch Master Curve, an experimental program has been completed composed of $168 \mathrm{CT}$ specimens, and covering six different notch radii (from $0 \mathrm{~mm}$ up to 2.0 $\mathrm{mm}$ ) and two different steels (S275JR and S355J2). Both materials have been tested at three different temperatures within their corresponding transition zone.

The application of the Notch Master Curve to the experimental results has provided good results, especially in steel S275JR. Steel 355J2 has presented several unsafe predictions, but it has generally provided reasonable results.

Finally, the use of the average value of the critical distance along the ductile-to-brittle transition zone has generally provided better results than the critical distance value provided by fitting equations.

\section{Acknowledgements}

The authors of this work would like to express their gratitude to the Spanish Ministry of Science and Innovation for the financial support of the project MAT2010-15721: 'Análisis de integridad estructural en defectos tipo entalla', on the results of which this paper is based.

\section{References}

[1] S. Cicero, V. Madrazo, I.A. Carrascal, Analysis of notch effect in PMMA by using the Theory of Critical Distances, Eng. Fract. Mech. 86 (2012) 56-72.

[2] V. Madrazo, S. Cicero, I.A. Carrascal, On the point method and the line method notch effect predictions in Al7075-T651, Eng. Fract. Mech. 79 (2012) 363-379.

[3] S. Cicero, V. Madrazo, T. García, J. Cuervo, E. Ruiz, On the notch effect in load bearing capacity, apparent fracture toughness and fracture mechanisms of polymer PMMA, aluminium alloy Al7075-T651 and structural steels S275JR and S355J2, Eng. Fail. Anal. 29 (2013) 108121.

[4] S. Cicero, V. Madrazo, T. García, Analysis of notch effect in the apparent fracture toughness and the fracture micromechanisms of ferritic-pearlitic steels operating within their lower shelf, Eng. Fail. Anal. Accepted, DOI 10.1016/j.engfailanal.2013.10.021

[5] Cicero, S., Madrazo, V., Carrascal, I.A., Cicero, R., Analysis of notch effect in fracture micromechanisms, Proceedings of ASME PVP2012, paper $n^{\circ}$ PVP2012-78008, Toronto, Canada, 2012 
[6] L.S. Niu, C. Chehimi, G. Pluvinage, Stress field near a large blunted V notch and application of the concept of notch stress intensity factor to the fracture of very brittle materials, Eng. Fract. Mech. 49 (1994) 325-335.

[7] G. Pluvinage, Fatigue and fracture emanating from notch; the use of the notch stress intensity factor, Nucl. Eng. Des. 185 (1998) 173-184.

[8] D. Taylor, The theory of critical distances: a new perspective in fracture mechanics. Elsevier, 2007.

[9] D. Taylor, P. Cornetti, N. Pugno, The fracture mechanics of finite crack extension, Eng. Fract. Mech. 72 (2005) 1021-1038.

[10] K. Wallin, The scatter in KIc results, Eng. Fract. Mech. 19 (1984) 1085-1093.

[11] K. Wallin, T. Saario, K. Törrönen, Statistical model for carbide induced brittle fracture in steel, Metal. Sci. 18 (1984) 13-16.

[12] K. Wallin, The size effect in KIC results, Eng. Fract. Mech. 22 (1985) 149-163.

[13] T.L. Anderson, Fracture mechanics: fundamentals and applications, Third ed., CRC Press. Florida, 2004.

[14] ASTM 1921-12, Test Method for the Determination of Reference Temperature T0 for Ferritic Steels in the Transition Range, American Society for Testing and Materials, ASTM, Philadelphia, 2012.

[15] H. Neuber, Theory of notch stresses: principles for exact calculation of strength with reference to structural form and material, Springer Verlag, Berlin, 1958.

[16] R.E. Peterson, Notch sensitivity, in: G. Sines, J.L Waisman, (Eds.): Metal fatigue, McGraw Hill, New York, 1959, pp. 293-306.

[17] D. Taylor, G. Wang, The validation of some methods of notch fatigue analysis, Fatig. Fract. Eng. Mater. Struct., 23 (2000) 387-394.

[18] D. Taylor, A mechanistic approach to critical-distance methods in notch fatigue, Fatig. Fract. Engng. Mater. Struct., 24 (2001) 215-224.

[19] L. Susmel, D. Taylor, Fatigue design in the presence of stress concentrations, J. Strain Anal. Eng. Des., 38 (2003) 443-52.

[20] D. Taylor, P. Bologna, K. Bel Knani, Prediction of fatigue failure location on a component using a critical distance method, Int. J. Fatig. 22 (2000) 735-742.

[21] L. Susmel, D. Taylor, On the use of the Theory of Critical Distances to predict failures in ductile metallic materials containing different geometrical features, Eng. Fract. Mech.75 (2008) 4410-4421.

[22] L. Susmel, D. Taylor, An elasto-plastic reformulation of the Theory of Critical Distances to estimate lifetime of notched components failing in the low/medium-cycle fatigue regime, J. Eng. Mat. Tech., Trans ASME 2010, 132 (2010) 0210021-210028.

[23] S. Cicero, V. Madrazo, I.A. Carrascal, On the Point Method load-bearing capacity predictions in Al7075-T651 structural components containing stress risers, Eng. Fail. Anal. 26 (2012) 129-138.

[24] M. Creager, C. Paris, Elastic Field Equations for Blunt Cracks with Reference to Stress Corrosion Cracking, Int. J. of Fract. 3 (1967) 247-252.

[25] S. Cicero, V. Madrazo, I.A. Carrascal, R. Cicero, Assessment of notched structural components using failure assessment diagrams and the theory of critical distances, Eng. Fract. Mech. 78 (2011) 2809-2825.

[26] K. Wallin, Master curve analysis of ductile to brittle transition region fracture toughness round robin data. The "EURO" fracture toughness curve, VTT Publications 367, JulkaisijaUtgivare Publisher, 1998 
[27] ASTM E8/E8M-09, Standard Test Methods for Tension Testing of Metallic Materials, ASTM, Philadelphia, 2009. 


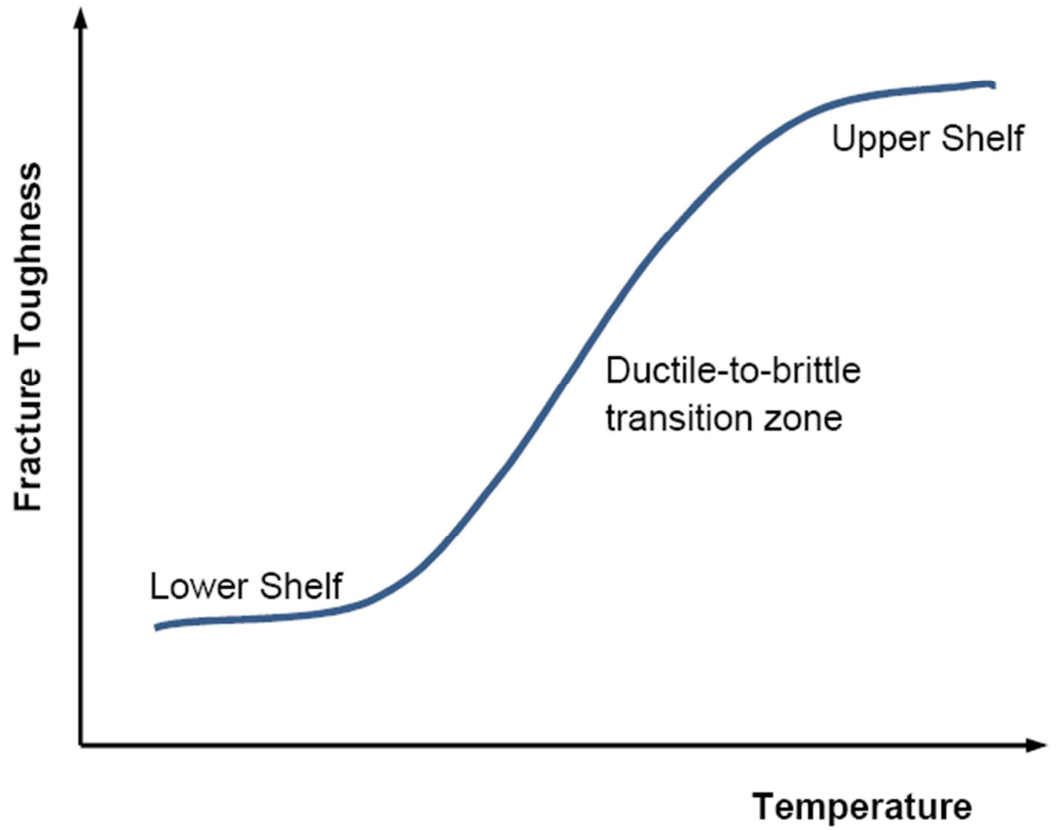

Figure 1. Schematic showing the different regions of fracture behaviour in ferritic-pearlitic steels. 


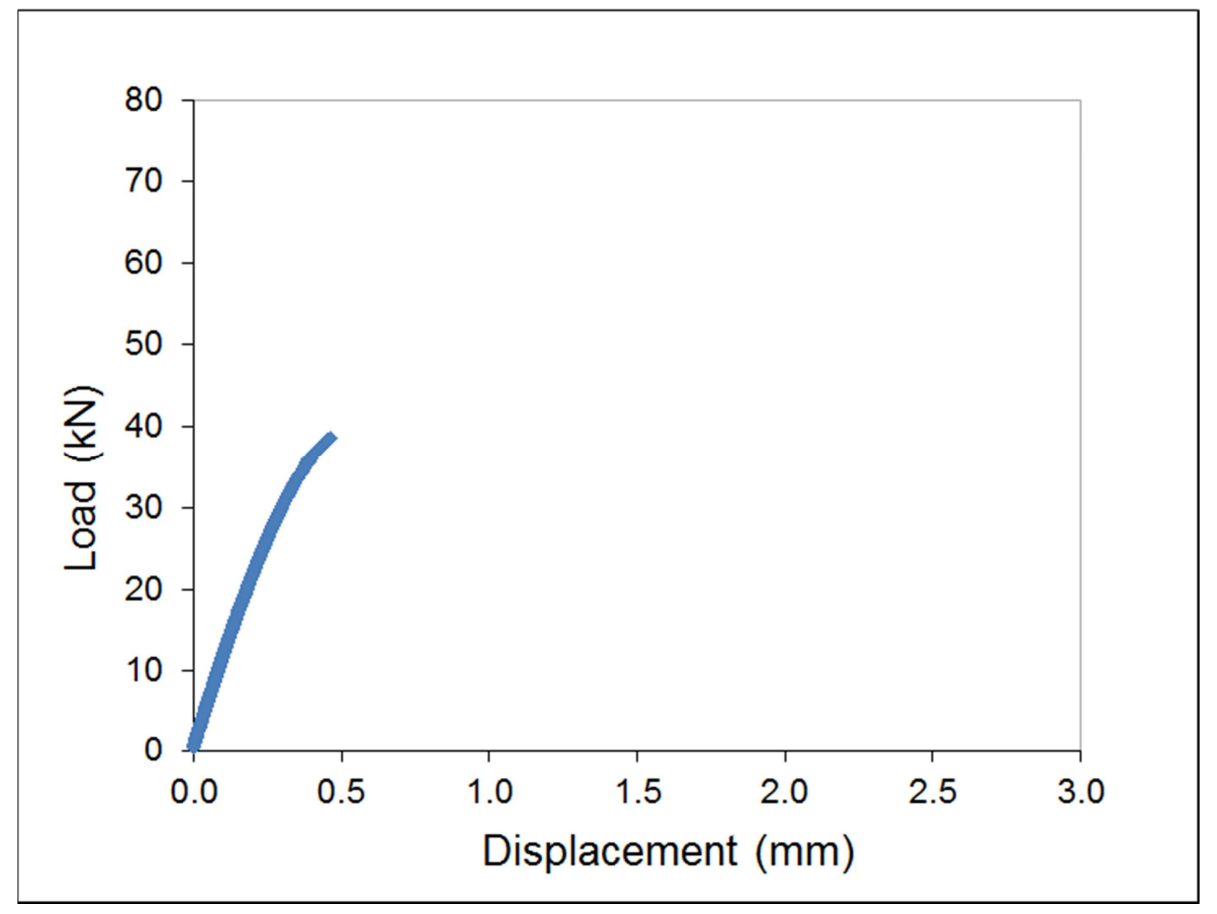

Figure 2. Load-displacement curve corresponding to specimen $2-750\left(\mathrm{~T}=-30^{\circ} \mathrm{C}\right.$, notch radius $=$ $0 \mathrm{~mm})$. 


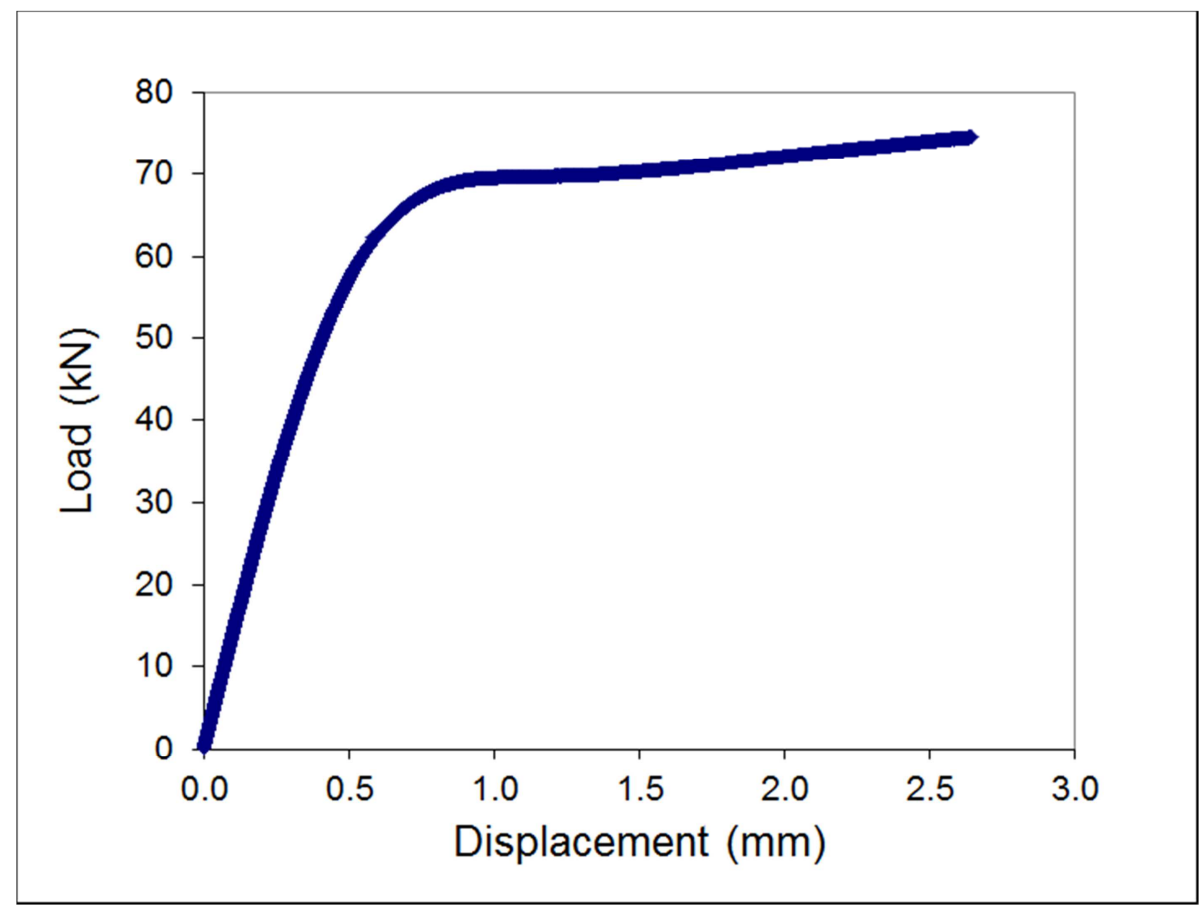

Figure 3. Load-displacement curve corresponding to specimen $3-80\left(\mathrm{~T}=-100^{\circ} \mathrm{C}\right.$, notch radius $=$ $0.15 \mathrm{~mm})$. 


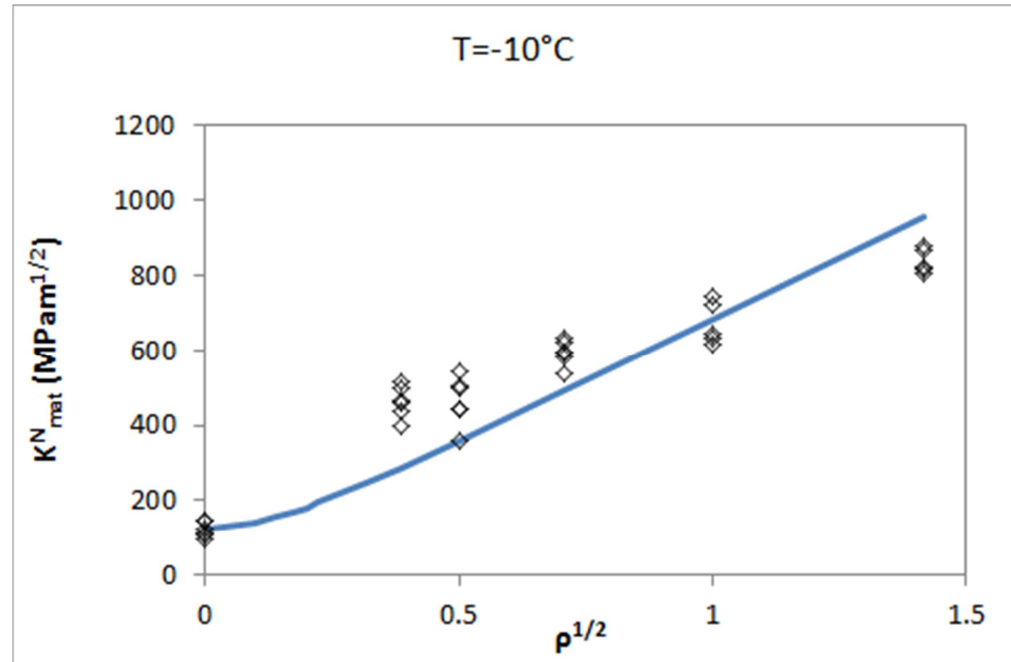

a)

$\diamond$ experimental results $L \mathrm{LM}$ predictions $(\mathrm{L}=0.0083 \mathrm{~mm})$

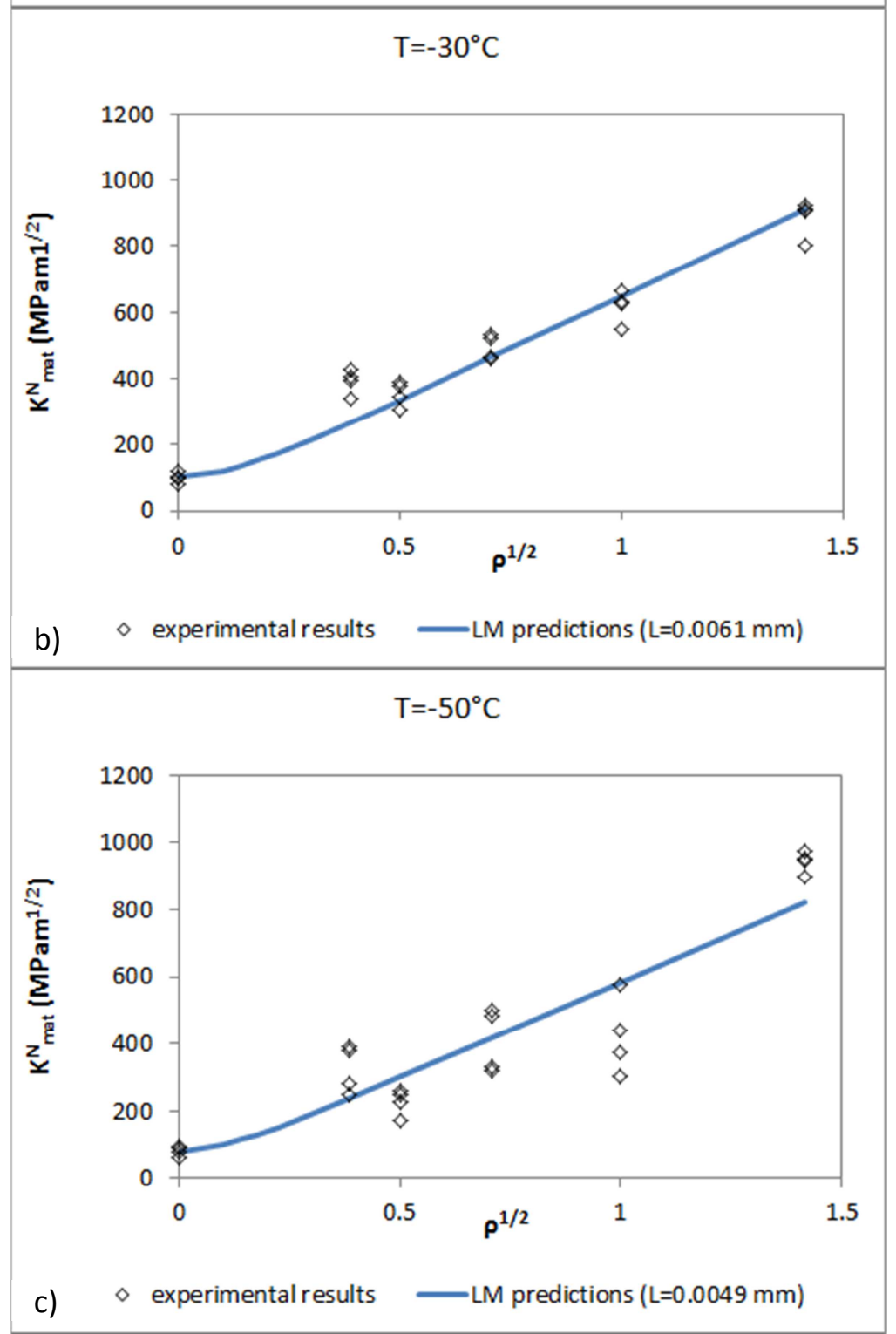

Figure 4. Apparent fracture toughness in steel S275JR: experimental results and LM best fit predictions: a) $-10^{\circ} \mathrm{C}$; b) $-30^{\circ} \mathrm{C}$; c) $-50^{\circ} \mathrm{C}$. 


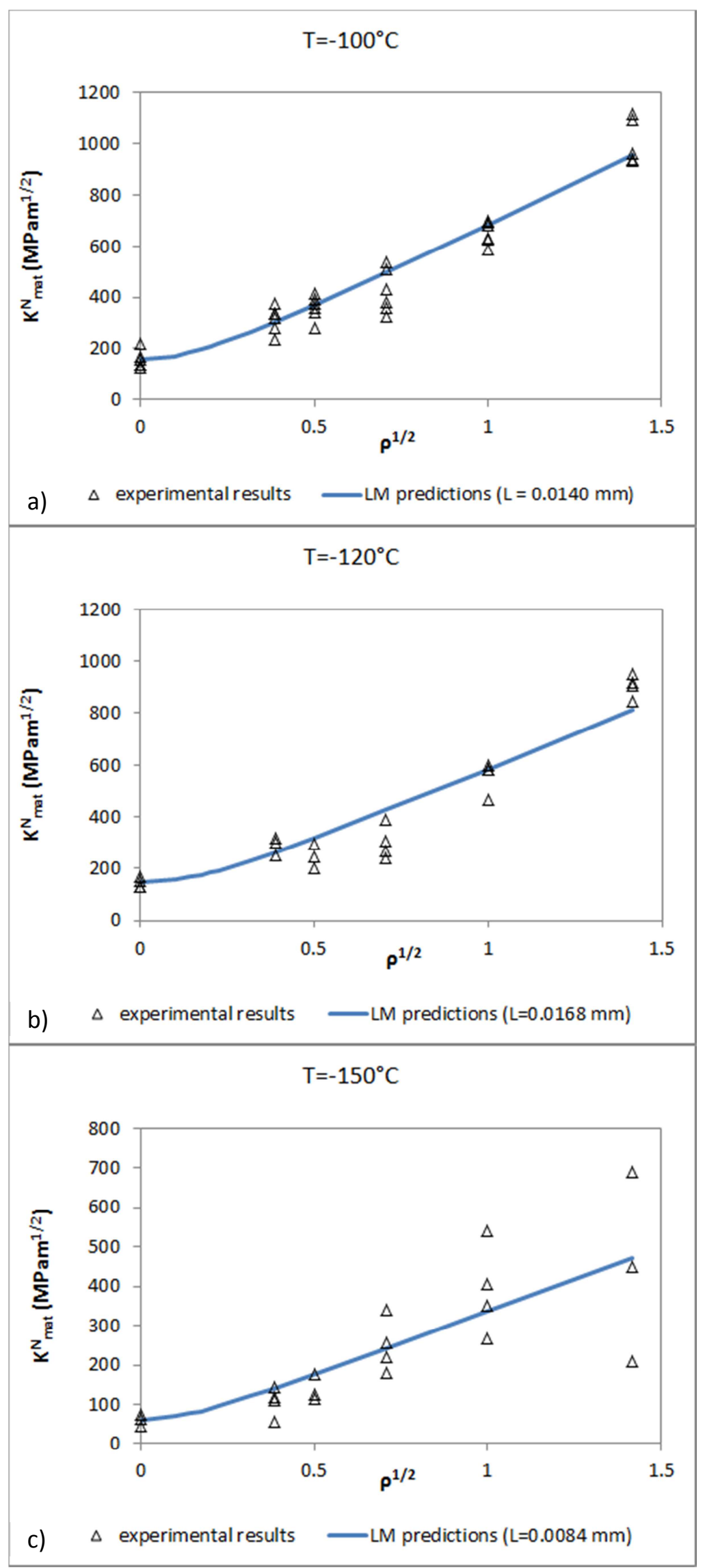

Figure 5. Apparent fracture toughness in steel S355J2: experimental results and LM best fit predictions: a) $-100^{\circ} \mathrm{C}$; b) $-120^{\circ} \mathrm{C}$; c) $-150^{\circ} \mathrm{C}$. 


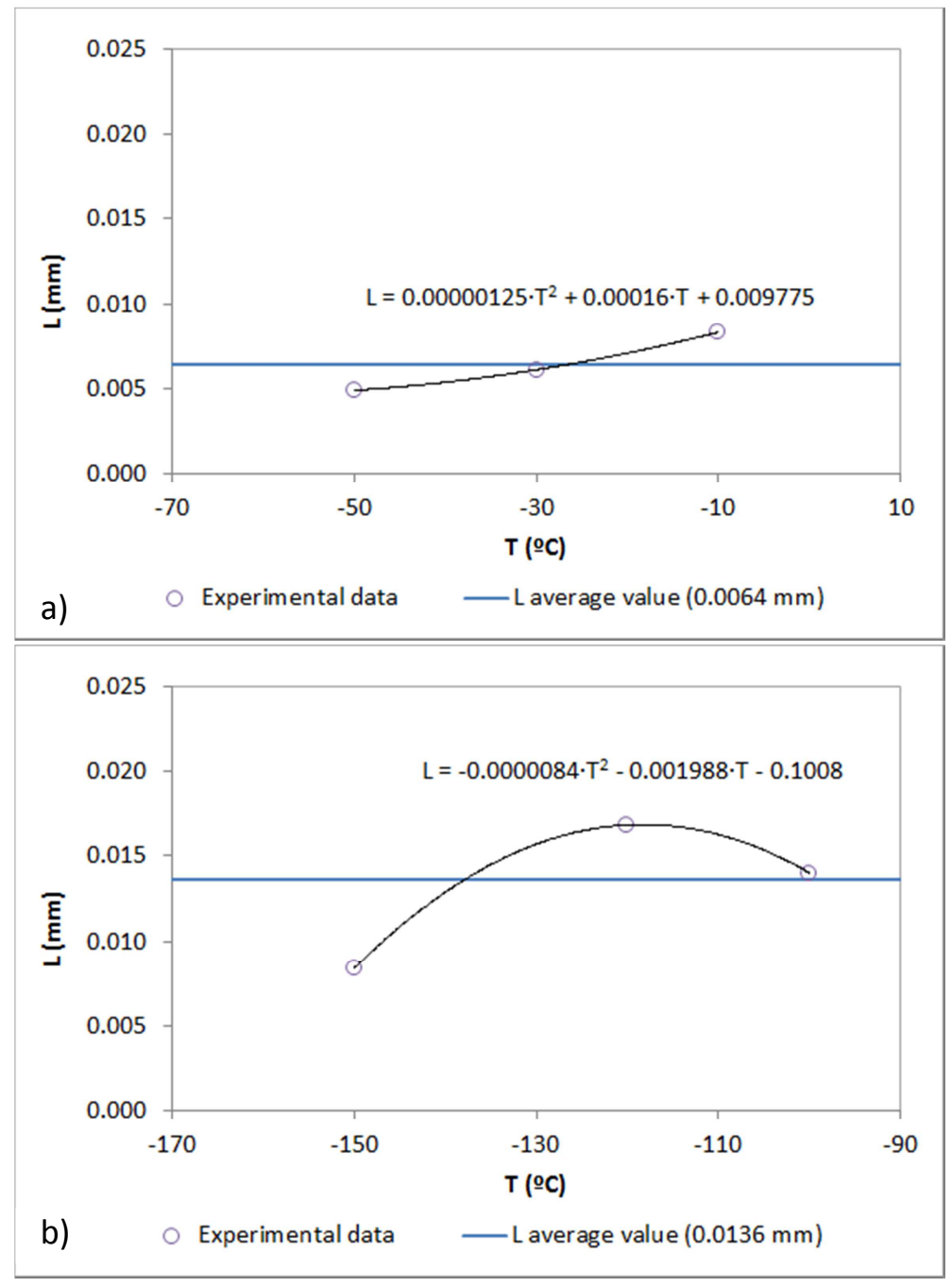

Figure 6. $L$ values at different temperatures, second order fitting equation and average value: a) steel S275JR; b) steel S355J2 


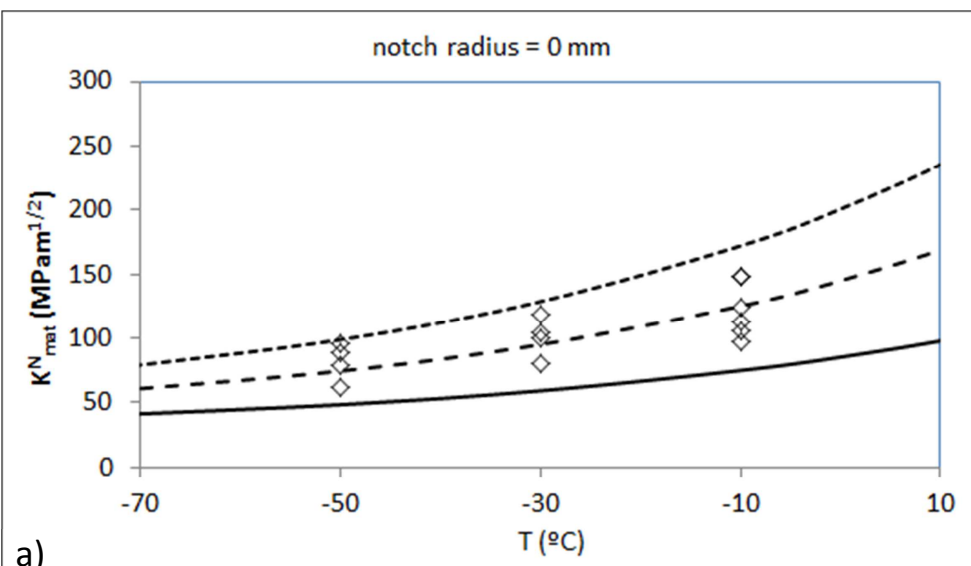

a)

$-\mathrm{KNJc}(5 \%)---\mathrm{KNJc}(50 \%)---\cdot \mathrm{KNJc}(95 \%) \diamond$ Experimental results

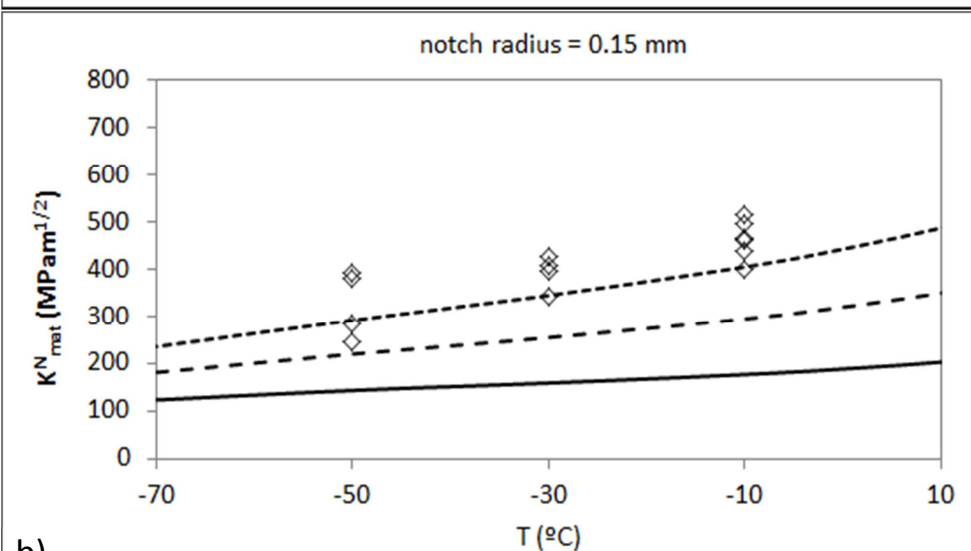

b)

$\mathrm{T}\left({ }^{\circ} \mathrm{C}\right)$

- KNJc $(5 \%)---K N J c(50 \%)---K N J c(95 \%) \diamond$ Experimental results

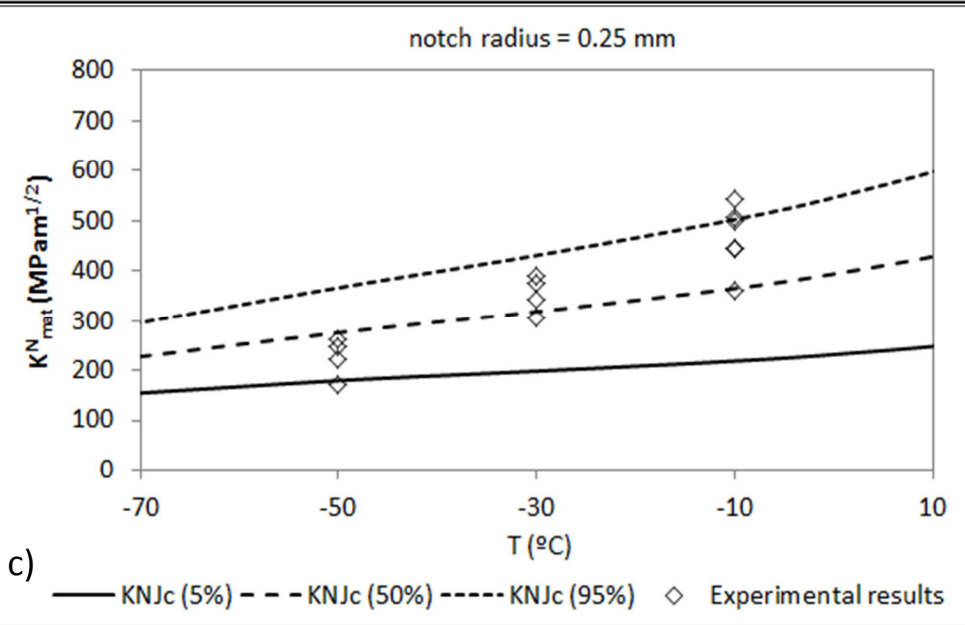

Figure 7. Comparison between experimental results and NMC predictions in steel S275JR. L following equation (19): a) notch radius $=0 \mathrm{~mm}$ (crack-like defect); b) notch radius $=0.15 \mathrm{~mm}$; c) notch radius $=0.25 \mathrm{~mm}$. 


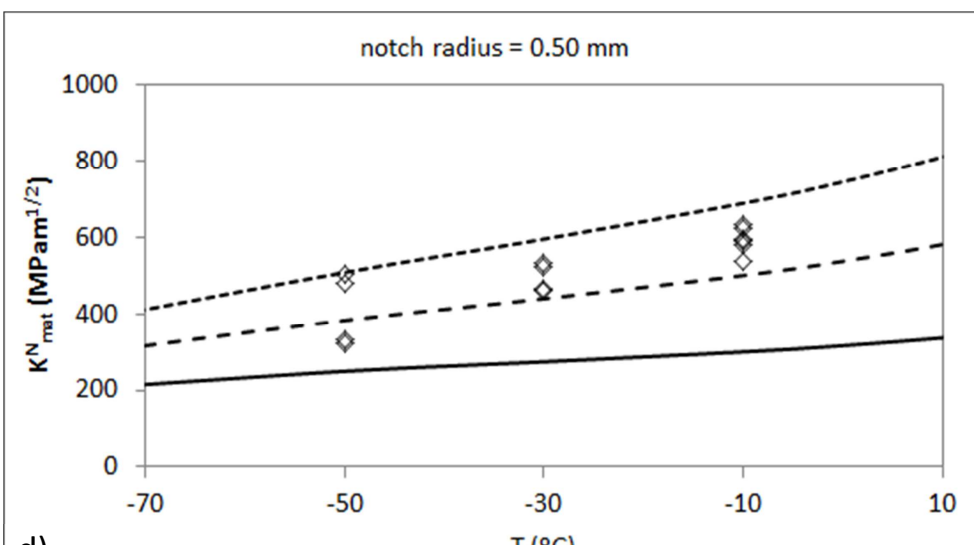

d)

$\mathrm{T}(\stackrel{\circ}{ } \mathrm{C})$
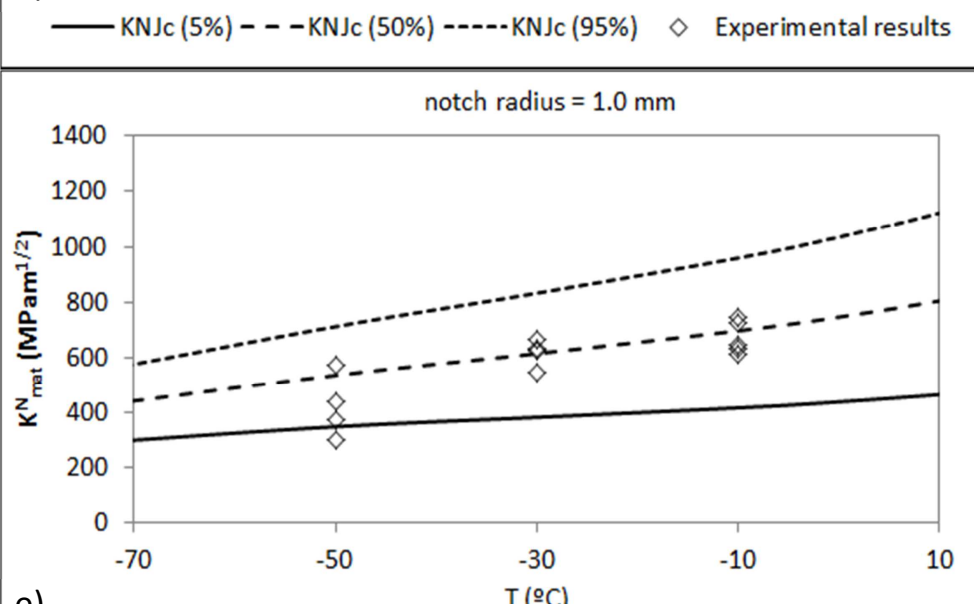

e)

$\mathrm{T}(\stackrel{\circ}{ } \mathrm{C})$

KNJc $(5 \%)---K N J c(50 \%)----K N J c(95 \%) \quad \diamond$ Experimental results

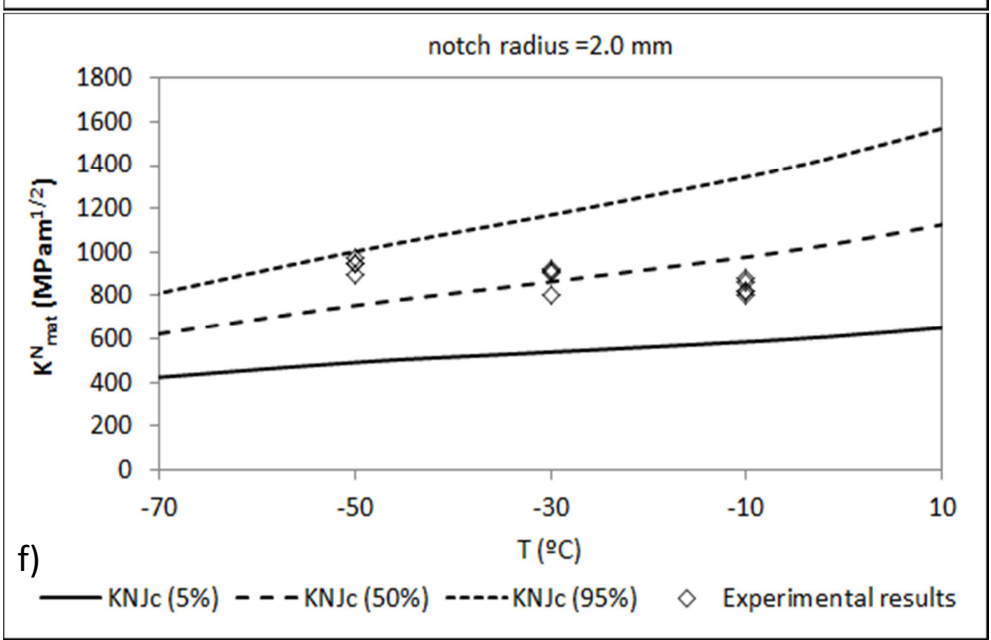

Figure7 (cont.). Comparison between experimental results and NMC predictions in steel S275JR. L following equation (19): d) notch radius $=0.5 \mathrm{~mm}$; ) notch radius $=1.0 \mathrm{~mm} ; \mathrm{f}$ ) notch radius $=2.0 \mathrm{~mm}$. 


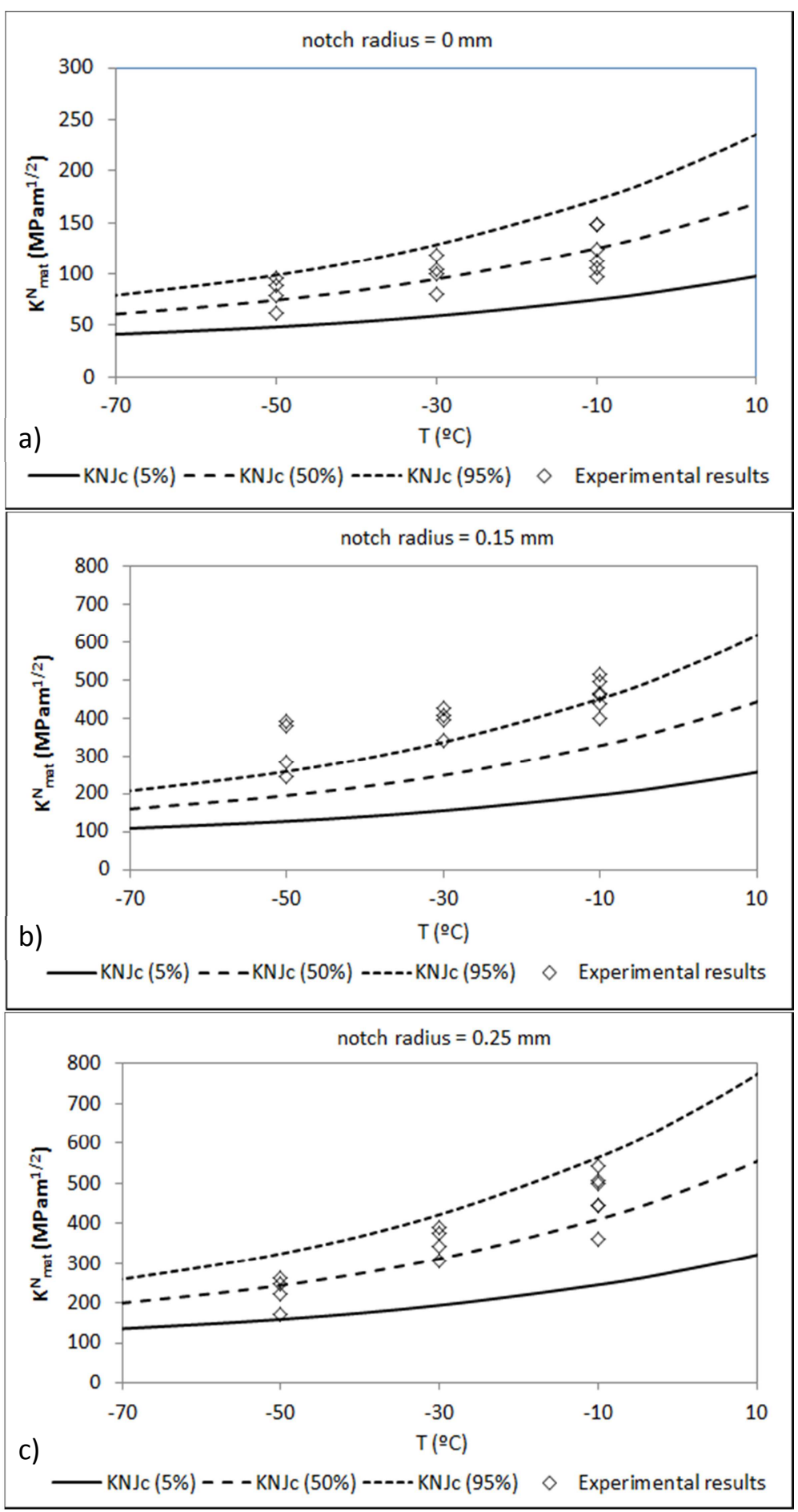

Figure 8. Comparison between experimental results and NMC predictions in steel S275JR. L= $0.0064 \mathrm{~mm}$ (average value): a) notch radius $=0 \mathrm{~mm}$ (crack-like defect); b) notch radius $=0.15$ $\mathrm{mm}$; $)$ notch radius $=0.25 \mathrm{~mm}$. 


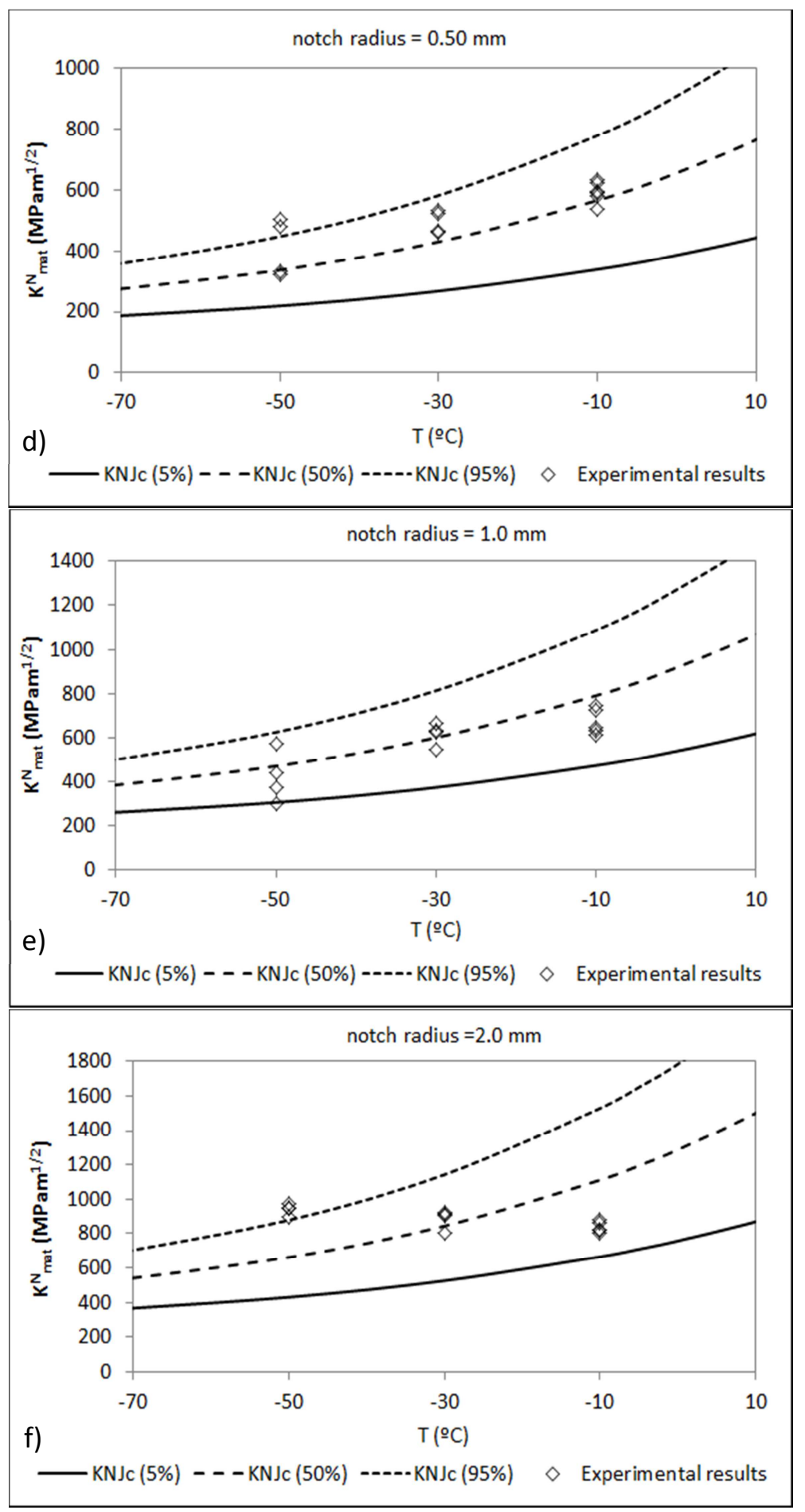

Figure 8 (cont.). Comparison between experimental results and NMC predictions in steel S275JR. L $=0.0064 \mathrm{~mm}$ (average value): $\mathrm{d}$ ) notch radius $=0.5 \mathrm{~mm}$; e) notch radius $=1.0 \mathrm{~mm} ; \mathrm{f}$ ) notch radius $=2.0 \mathrm{~mm}$. 


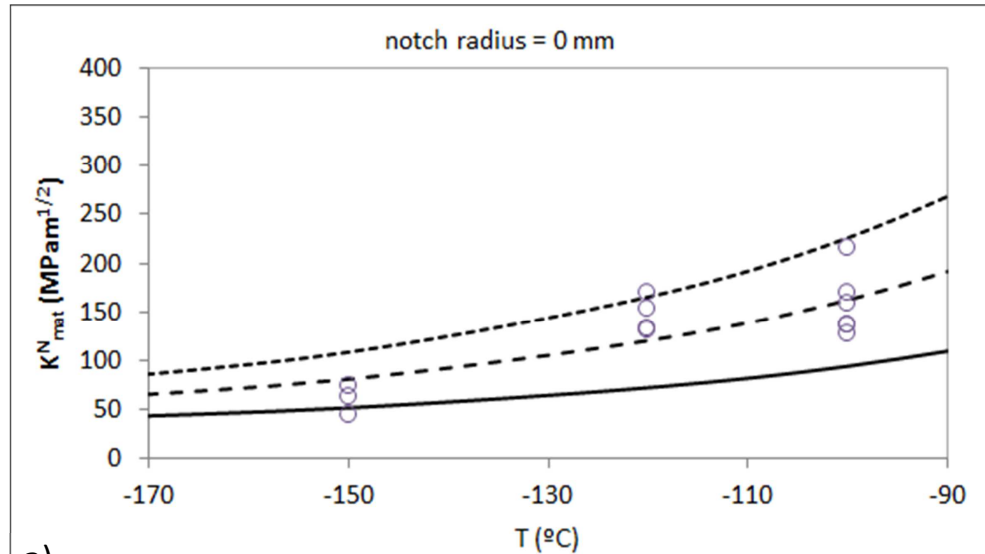

a)

- KNJc (5\%) - - - KNJc (50\%) ---.. KNJc (95\%) ○ Experimental results

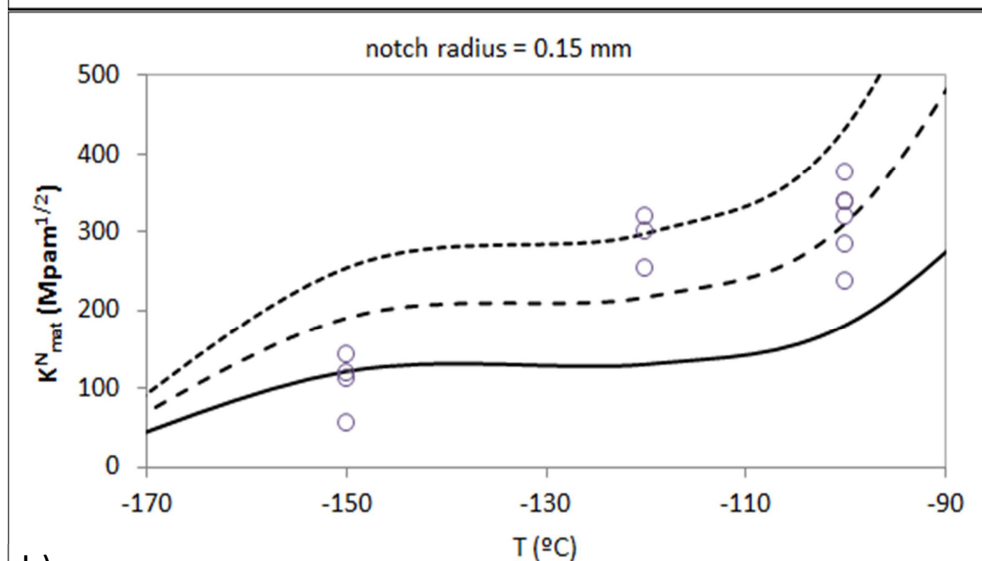

b)

- KNJc $(5 \%)---K N J c(50 \%)--\cdot K N J c(95 \%) \quad \bigcirc \quad$ Experimental results

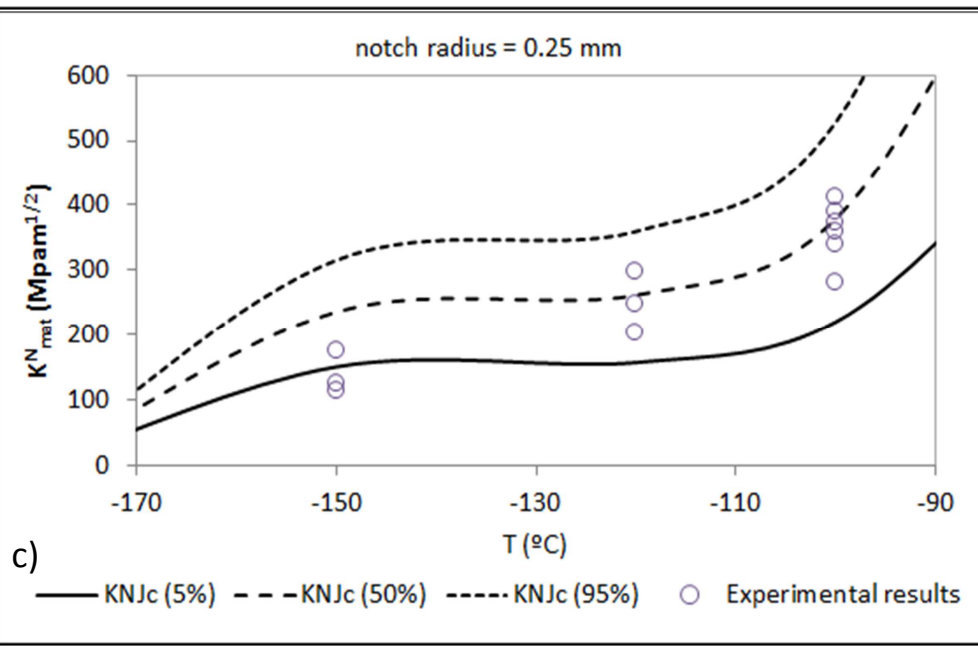

Figure 9. Comparison between experimental results and NMC predictions in steel S355J2. L following equation (20): a) notch radius $=0 \mathrm{~mm}$ (crack-like defect); b) notch radius $=0.15 \mathrm{~mm}$; c) notch radius $=0.25 \mathrm{~mm}$. 


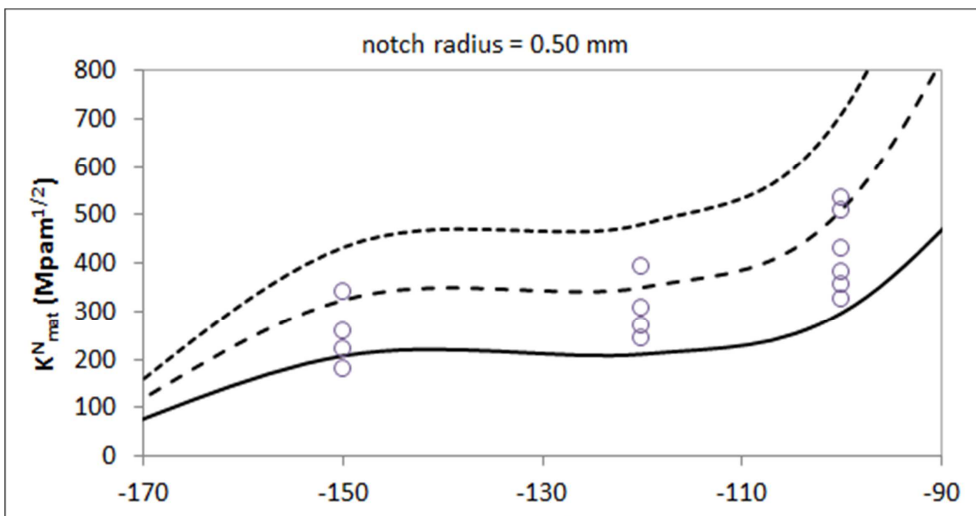

d)

$\mathrm{T}\left({ }^{\circ} \mathrm{C}\right)$

- KNJc $(5 \%)---$ KNJc $(50 \%)---\cdot$ KNJc $(95 \%) \quad \bigcirc$ Experimental results

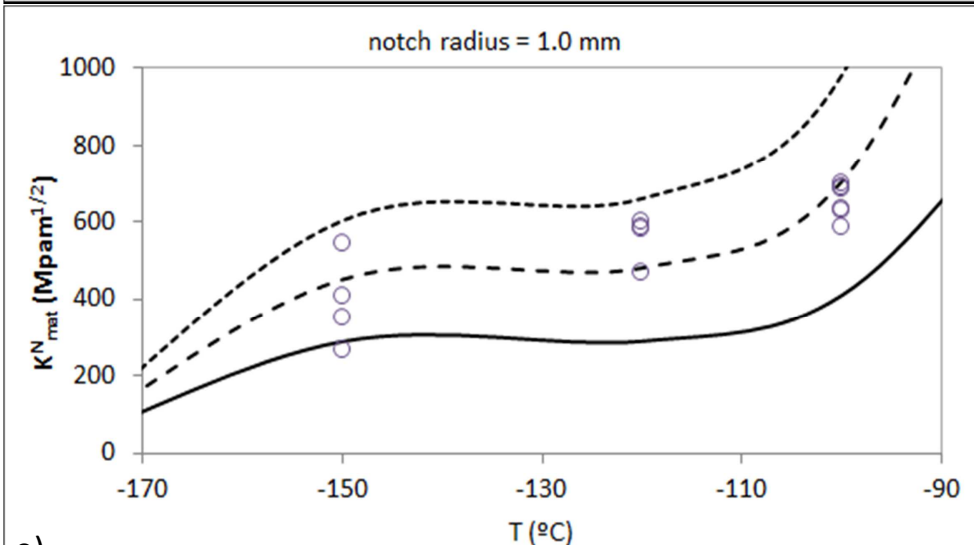

e)

- KNJc $(5 \%)---K N J c(50 \%)--\cdot K N J c(95 \%) \quad \bigcirc$ Experimental results

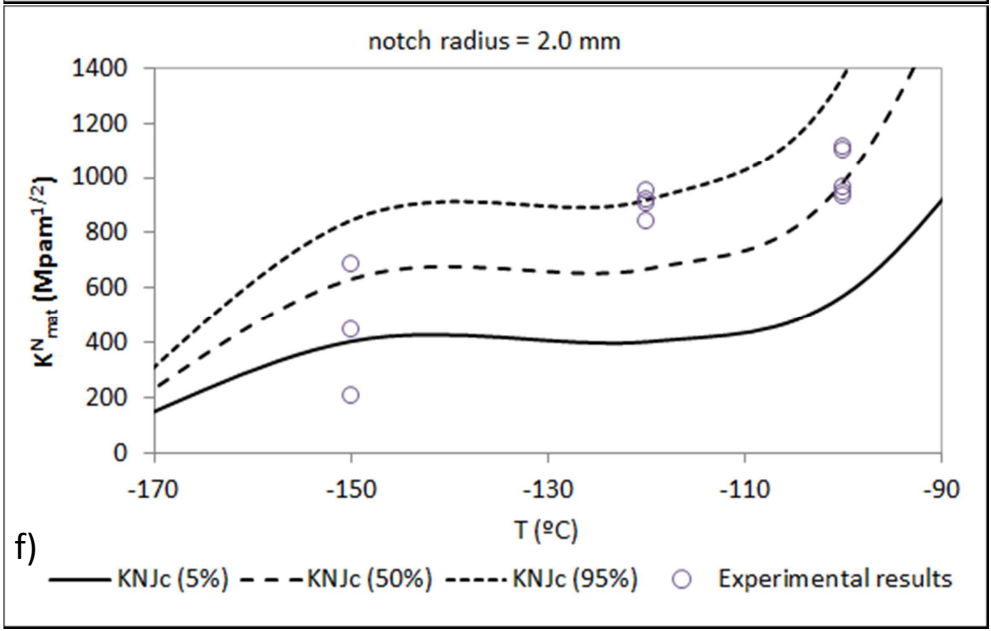

Figure 9 (cont.). Comparison between experimental results and NMC predictions in steel $\mathrm{S} 355 \mathrm{~J} 2$. L following equation (20): $\mathrm{d}$ ) notch radius $=0.5 \mathrm{~mm}$; e) notch radius $=1.0 \mathrm{~mm} ; \mathrm{f}$ ) notch radius $=2.0 \mathrm{~mm}$. 


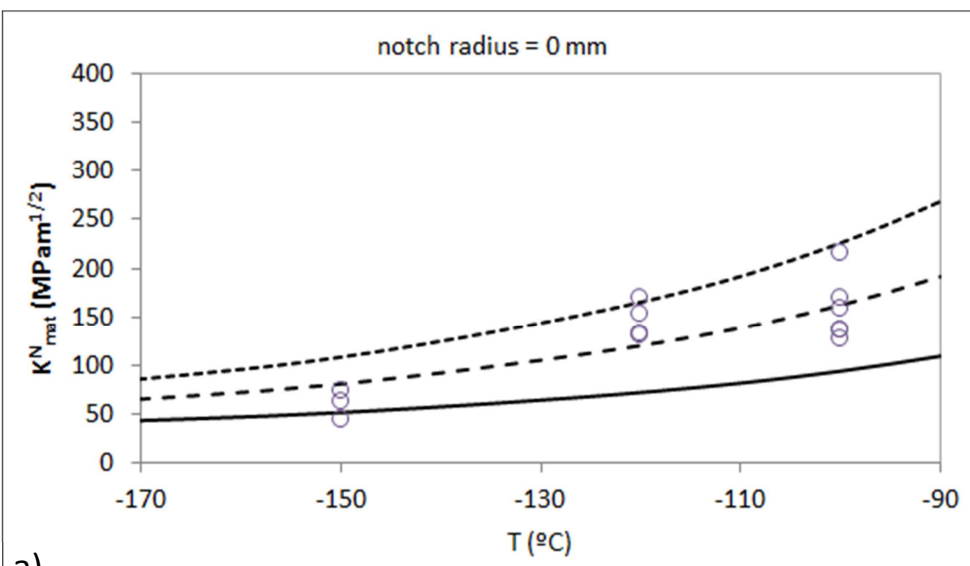

a)

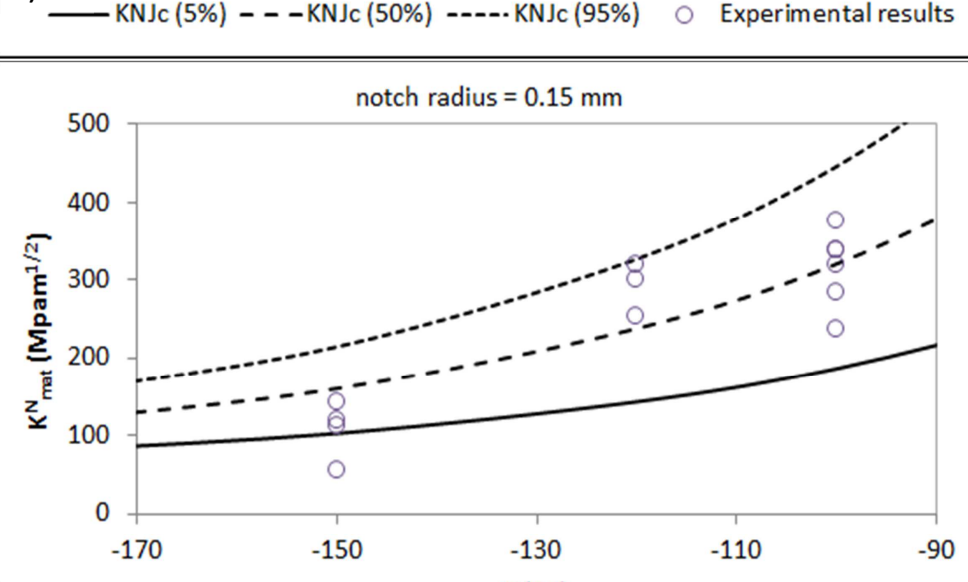

b)

$\mathrm{T}(\stackrel{\circ}{\mathrm{C}})$
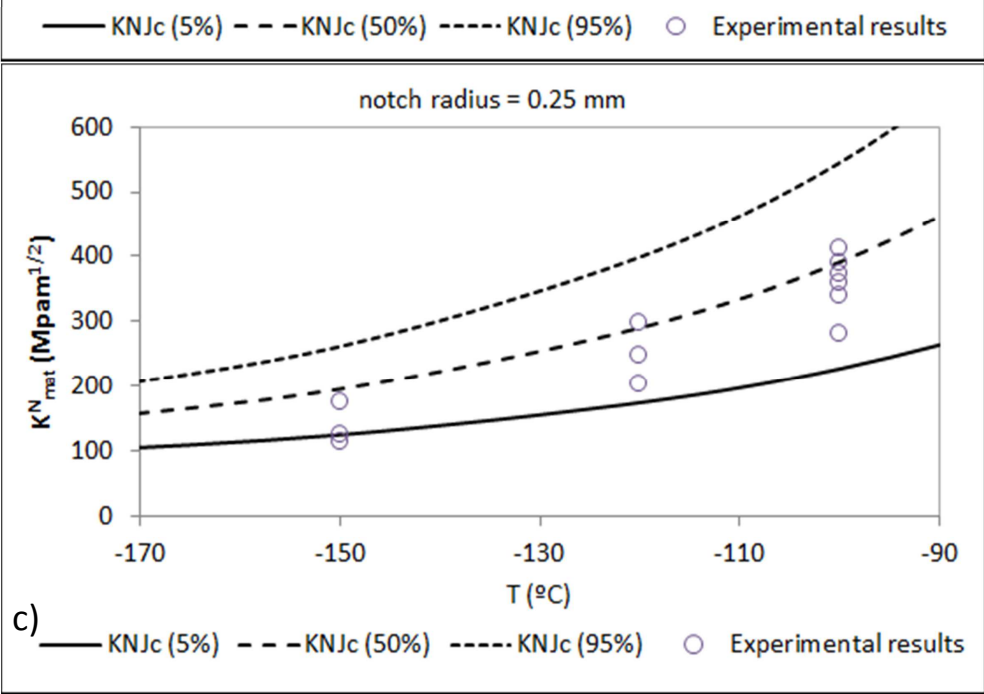

Figure 10. Comparison between experimental results and NMC predictions in steel S355J2. L= $0.0136 \mathrm{~mm}$ (average value): a) notch radius $=0 \mathrm{~mm}$ (crack-like defect); $\mathrm{b}$ ) notch radius $=0.15$ $\mathrm{mm} ; \mathrm{c}$ ) notch radius $=0.25 \mathrm{~mm}$. 


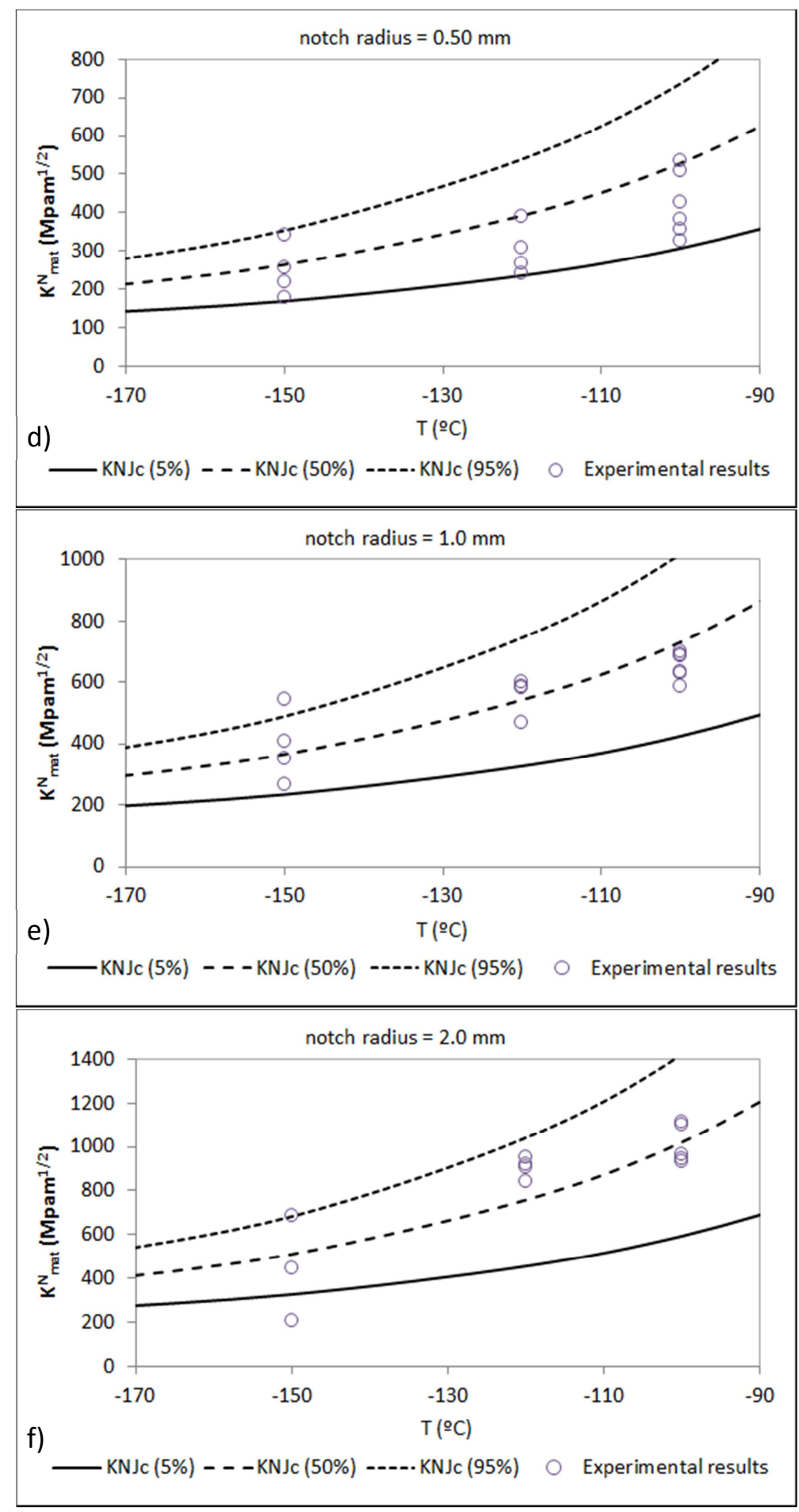

Figure 10 (cont.). Comparison between experimental results and NMC predictions in steel $\mathrm{S} 355 \mathrm{~J} 2 . \mathrm{L}=0.0136 \mathrm{~mm}$ (average value): $\mathrm{d}$ ) notch radius $=0.5 \mathrm{~mm}$; ) notch radius $=1.0 \mathrm{~mm} ; \mathrm{f}$ ) notch radius $=2.0 \mathrm{~mm}$. 


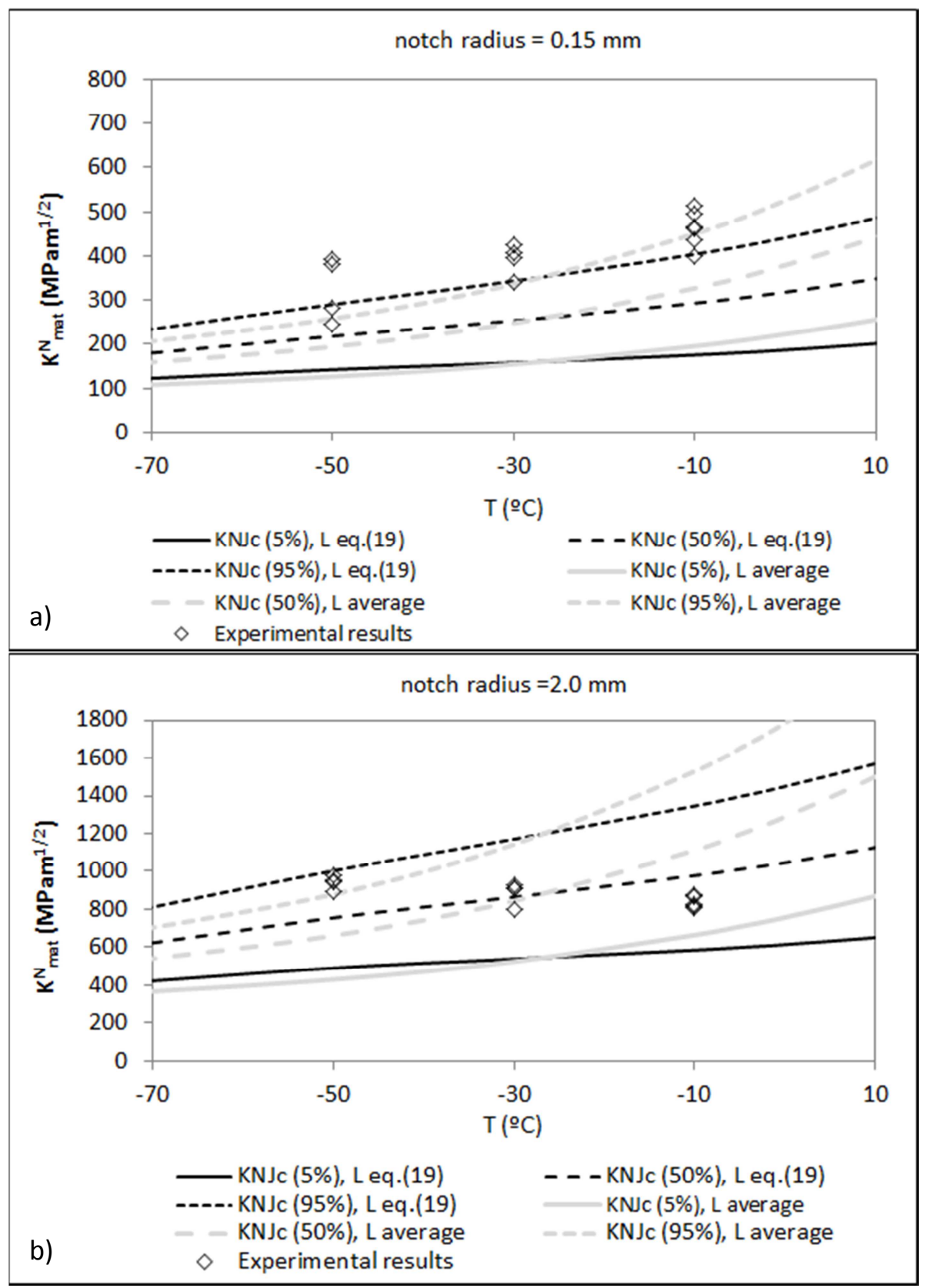

Figure 11. Comparison between experimental results and NMC predictions in steel S275JR provided by the average value of $\mathrm{L}$ and the value of $\mathrm{L}$ obtained by using equation (19). a) notch radius $=0.15 \mathrm{~mm} ; \mathrm{b}$ ) notch radius $=2.0 \mathrm{~mm}$. 


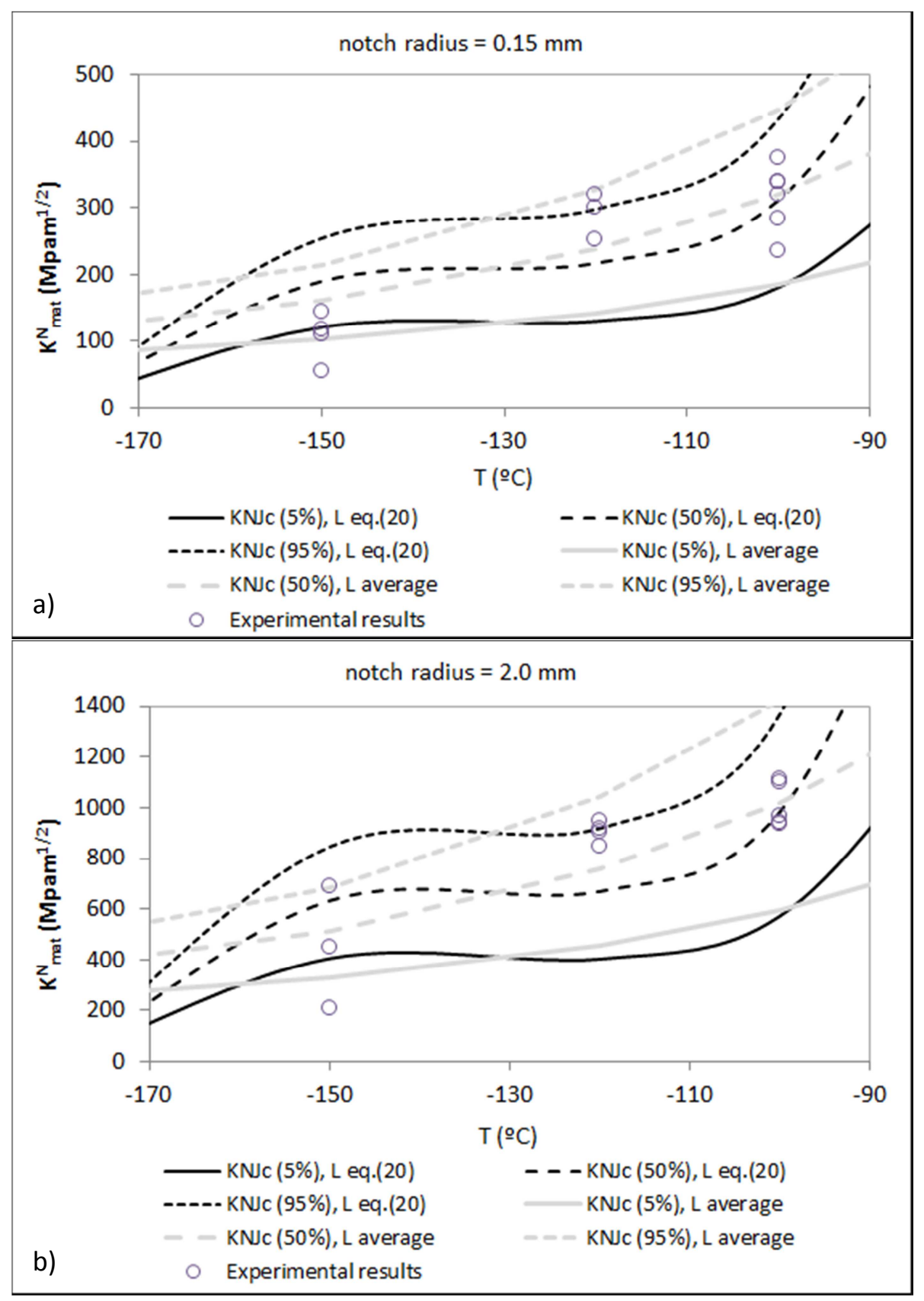

Figure 12. Comparison between experimental results and NMC predictions in steel S355J2 provided by the average value of $L$ and the value of $L$ obtained by using equation (20). a) notch radius $=0.15 \mathrm{~mm}$; $\mathrm{b}$ ) notch radius $=2.0 \mathrm{~mm}$. 
Table 1. Tensile properties of the two materials being analysed.

\begin{tabular}{|c|c|c|c|c|}
\hline Material & Temperature $\left({ }^{\mathbf{0}} \mathbf{C}\right)$ & $\mathbf{E}(\mathbf{G P a})$ & $\boldsymbol{\sigma}_{\mathbf{v}}(\mathbf{M P a})$ & $\boldsymbol{\sigma}_{\mathbf{u}}(\mathbf{M P a})$ \\
\hline \multirow{3}{*}{ S275JR } & -10 & 207 & 337.6 & 536.3 \\
\cline { 2 - 5 } & -30 & 208 & 344.5 & 548.6 \\
\cline { 2 - 5 } & -50 & 209 & 349.1 & 564.7 \\
\hline \multirow{3}{*}{ S355J2 } & -100 & 212 & 426.2 & 646.5 \\
\cline { 2 - 5 } & -120 & 212 & 459.8 & 671.6 \\
\cline { 2 - 5 } & -150 & 215 & 527.5 & 757.9 \\
\hline
\end{tabular}


Table 2. Description of specimens and experimental results. Steel S275JR.

\begin{tabular}{|c|c|c|c|c|c|c|c|}
\hline Specimen & $\begin{array}{c}\text { Temperature } \\
\left({ }^{\circ} \mathrm{C}\right)\end{array}$ & $\left.\begin{array}{c}\mathbf{\rho} \\
(\mathbf{m m})\end{array}\right)$ & $\begin{array}{c}\left.\mathbf{K}^{\mathbf{N}} \text { mat }^{1 / 2}\right) \\
\left(\mathbf{M P a m}^{1 / 2}\right)\end{array}$ & Specimen & $\begin{array}{c}\text { Temperature } \\
\left({ }^{\circ} \mathrm{C}\right)\end{array}$ & $\begin{array}{c}\rho \\
(\mathbf{m m})\end{array}$ & $\begin{array}{c}\mathbf{K}^{\mathbf{N}}{ }_{\text {mat }} \\
\left(\mathbf{M P a m}^{\mathbf{1} 2}\right)\end{array}$ \\
\hline $2-49$ & \multirow{24}{*}{$\begin{array}{c}-50 \\
(\mathrm{DBTZ})\end{array}$} & \multirow{4}{*}{0} & 61.3 & 2-97 & \multirow{36}{*}{$\begin{array}{c}-10 \\
(\mathrm{DBTZ})\end{array}$} & \multirow{6}{*}{0} & 148.5 \\
\hline $2-50$ & & & 88.0 & $2-98$ & & & 97.0 \\
\hline $2-51$ & & & 78.1 & $2-99$ & & & 105.8 \\
\hline $2-52$ & & & 95.0 & $2-100$ & & & 124.2 \\
\hline $2-53$ & & \multirow{4}{*}{0.15} & 283.2 & $2-101$ & & & 148.1 \\
\hline $2-54$ & & & 246.3 & $2-102$ & & & 113.2 \\
\hline $2-55$ & & & 392.5 & $2-103$ & & \multirow{6}{*}{0.15} & 400.2 \\
\hline $2-56$ & & & 379.9 & $2-104$ & & & 465.0 \\
\hline $2-57$ & & \multirow{4}{*}{0.25} & 223.7 & $2-105$ & & & 496.7 \\
\hline $2-58$ & & & 260.9 & $2-106$ & & & 461.1 \\
\hline $2-59$ & & & 246.6 & $2-107$ & & & 435.6 \\
\hline $2-60$ & & & 169.9 & $2-108$ & & & 514.3 \\
\hline $2-61$ & & \multirow{4}{*}{0.50} & 330.1 & $2-109$ & & \multirow{6}{*}{0.25} & 444.2 \\
\hline $2-62$ & & & 321.8 & $2-110$ & & & 444.1 \\
\hline $2-63$ & & & 501.9 & $2-111$ & & & 499.0 \\
\hline $2-64$ & & & 481.9 & $2-112$ & & & 544.5 \\
\hline $2-65$ & & \multirow{4}{*}{1.0} & 302.5 & $2-113$ & & & 504.8 \\
\hline $2-66$ & & & 437.7 & $2-114$ & & & 360.3 \\
\hline $2-67$ & & & 374.0 & $2-115$ & & \multirow{12}{*}{0.50} & 535.6 \\
\hline $2-68$ & & & 575.2 & $2-116$ & & & 634.1 \\
\hline $2-69$ & & \multirow{4}{*}{2.0} & 950.3 & 2-117 & & & 591.8 \\
\hline $2-70$ & & & 976.2 & $2-118$ & & & 593.2 \\
\hline $2-71$ & & & 947.4 & $2-119$ & & & 622.2 \\
\hline $2-72$ & & & 897.2 & $2-120$ & & & 582.9 \\
\hline $2-73$ & \multirow{24}{*}{$\begin{array}{c}-30 \\
\text { (DBTZ) }\end{array}$} & \multirow{4}{*}{0} & 104.2 & $2-121$ & & & - \\
\hline $2-74$ & & & 80.8 & $2-122$ & & & 615.3 \\
\hline $2-75$ & & & 100.1 & $2-123$ & & & 645.6 \\
\hline $2-76$ & & & 117.7 & $2-124$ & & & 723.8 \\
\hline $2-77$ & & & 395.3 & $2-125$ & & & 746.3 \\
\hline $2-78$ & & & 426.1 & $2-126$ & & & 629.8 \\
\hline $2-79$ & & 0.15 & 405.3 & $2-127$ & & & 817.3 \\
\hline $2-80$ & & & 339.8 & $2-128$ & & & - \\
\hline $2-81$ & & & 390.1 & $2-129$ & & 20 & 866.3 \\
\hline $2-82$ & & $0>2$ & 376.4 & $2-130$ & & 2.0 & 878.7 \\
\hline $2-83$ & & $0.2 J$ & 343.3 & $2-131$ & & & 822.0 \\
\hline $2-84$ & & & 306.9 & $2-132$ & & & 804.1 \\
\hline $2-85$ & & & 460.4 & & & & \\
\hline $2-86$ & & 050 & 524.2 & & & & \\
\hline $2-87$ & & .00 & 533.7 & & & & \\
\hline $2-88$ & & & 468.0 & & & & \\
\hline $2-89$ & & & 632.3 & & & & \\
\hline $2-90$ & & 10 & 624.1 & & & & \\
\hline 2-91 & & 1.0 & 547.7 & & & & \\
\hline $2-92$ & & & 667.1 & & & & \\
\hline $2-93$ & & & 906.5 & & & & \\
\hline $2-94$ & & 20 & 801.9 & & & & \\
\hline $2-95$ & & 2.0 & 911.6 & & & & \\
\hline $2-96$ & & & 924.3 & & & & \\
\hline
\end{tabular}


Table 3. Description of specimens and experimental results. Steel S355J2.

\begin{tabular}{|c|c|c|c|c|c|c|c|}
\hline Specimen & $\begin{array}{c}\text { Temperature } \\
\left({ }^{\circ} \mathrm{C}\right)\end{array}$ & $\left.\begin{array}{c}\rho \\
(\mathbf{m m})\end{array}\right)$ & \begin{tabular}{|c|}
$\mathbf{K}^{\mathbf{N}}{ }_{\text {mat }}$ \\
$\left(\mathbf{M P a m}^{1 / 2}\right)$
\end{tabular} & Specimen & $\begin{array}{c}\text { Temperature } \\
\left({ }^{\circ} \mathrm{C}\right)\end{array}$ & $\left.\begin{array}{c}\boldsymbol{\rho} \\
(\mathbf{m m})\end{array}\right)$ & $\begin{array}{c}\mathbf{K}^{\mathrm{N}} \text { mat }^{1 / 2} \\
\left(\mathbf{M P a m}^{1 / 2}\right)\end{array}$ \\
\hline 3-25 & \multirow{24}{*}{$\begin{array}{c}-150 \\
\text { (DBTZ) }\end{array}$} & \multirow{4}{*}{0} & - & 3-73 & \multirow{36}{*}{$\begin{array}{c}-100 \\
(\mathrm{DBTZ})\end{array}$} & \multirow{6}{*}{0} & 136.9 \\
\hline $3-26$ & & & 44.3 & 3-74 & & & 136.1 \\
\hline 3-27 & & & 63.3 & $3-75$ & & & 126.8 \\
\hline $3-28$ & & & 74.1 & 3-76 & & & 216.6 \\
\hline 3-29 & & \multirow{4}{*}{0.15} & 143.2 & 3-77 & & & 170.5 \\
\hline 3-30 & & & 54.8 & 3-78 & & & 158.0 \\
\hline 3-31 & & & 118.0 & 3-79 & & \multirow{6}{*}{0.15} & 236.1 \\
\hline 3-32 & & & 110.9 & $3-80$ & & & 374.7 \\
\hline 3-33 & & \multirow{4}{*}{0.25} & 126.8 & $3-81$ & & & 319.6 \\
\hline 3-34 & & & 175.8 & 3-82 & & & 337.8 \\
\hline 3-35 & & & 115.1 & 3-83 & & & 337.8 \\
\hline 3-36 & & & - & 3-84 & & & 282.7 \\
\hline 3-37 & & \multirow{4}{*}{0.50} & 220.2 & $3-85$ & & \multirow{6}{*}{0.25} & 412.9 \\
\hline 3-38 & & & 341.7 & $3-86$ & & & 390.0 \\
\hline 3-39 & & & 256.9 & 3-87 & & & 360.6 \\
\hline $3-40$ & & & 179.0 & $3-88$ & & & 373.5 \\
\hline 3-41 & & \multirow{4}{*}{1.0} & 266.4 & 3-89 & & & 340.1 \\
\hline $3-42$ & & & 407.4 & 3-90 & & & 282.8 \\
\hline $3-43$ & & & 541.7 & 3-91 & & \multirow{6}{*}{0.5} & 326.3 \\
\hline 3-44 & & & 350.5 & 3-92 & & & 534.9 \\
\hline $3-45$ & & \multirow{8}{*}{2.0} & 688.7 & 3-93 & & & 507.5 \\
\hline $3-46$ & & & - & 3-94 & & & 357.3 \\
\hline 3-47 & & & 448.0 & 3-95 & & & 383.7 \\
\hline $3-48$ & & & 208.8 & $3-96$ & & & 428.8 \\
\hline $3-49$ & \multirow{24}{*}{$\begin{array}{c}-120 \\
(\mathrm{DBTZ})\end{array}$} & & 169.5 & 3-97 & & \multirow{6}{*}{1.0} & 629.2 \\
\hline $3-50$ & & & 153.4 & 3-98 & & & 698.8 \\
\hline $3-51$ & & & 132.6 & 3-99 & & & 683.3 \\
\hline $3-52$ & & & 130.9 & 3-100 & & & 586.1 \\
\hline $3-53$ & & & 318.6 & 3-101 & & & 691.7 \\
\hline $3-54$ & & 015 & - & 3-102 & & & 632.1 \\
\hline $3-55$ & & 0.15 & 300.0 & 3-103 & & & 932.9 \\
\hline $3-56$ & & & 253.0 & 3-104 & & & 964.9 \\
\hline $3-57$ & & & - & 3-105 & & 20 & 1115.7 \\
\hline 3-58 & & 025 & 297.9 & 3-106 & & 2.0 & 1097.2 \\
\hline 3-59 & & $0.2 J$ & 203.4 & 3-107 & & & 942.4 \\
\hline $3-60$ & & & 248.8 & 3-108 & & & - \\
\hline 3-61 & & & 241.8 & & & & \\
\hline 3-62 & & 050 & 391.7 & & & & \\
\hline 3-63 & & 0.50 & 307.9 & & & & \\
\hline 3-64 & & & 269.4 & & & & \\
\hline 3-65 & & & 581.9 & & & & \\
\hline 3-66 & & 10 & 584.1 & & & & \\
\hline $3-67$ & & 1.0 & 599.5 & & & & \\
\hline $3-68$ & & & 466.9 & & & & \\
\hline 3-69 & & & 904.4 & & & & \\
\hline 3-70 & & 20 & 844.4 & & & & \\
\hline 3-71 & & 2.0 & 918.0 & & & & \\
\hline 3-72 & & & 950.2 & & & & \\
\hline
\end{tabular}


Table 4. L values for steels S275JR and S355J2.

\begin{tabular}{|c|c|c|}
\hline Steel & Temperature $\left({ }^{\circ} \mathbf{C}\right)$ & $\mathbf{L}(\mathbf{m m})$ \\
\hline & -10 & 0.0083 \\
\cline { 2 - 3 } S275JR & -30 & 0.0061 \\
\cline { 2 - 3 } & -50 & 0.0049 \\
\hline \multirow{3}{*}{ S355J2 } & -100 & 0.0140 \\
\cline { 2 - 3 } & -120 & 0.0168 \\
\cline { 2 - 3 } & -150 & 0.0084 \\
\hline
\end{tabular}

